IZA DP No. 9502

Bright Minds, Big Rent:

Gentrification and the Rising Returns to Skill

Lena Edlund

Cecilia Machado

Maria Sviatschi

November 2015 


\title{
Bright Minds, Big Rent: Gentrification and the Rising Returns to Skill
}

\author{
Lena Edlund \\ Columbia University \\ Cecilia Machado \\ Getulio Vargas Foundation \\ and IZA \\ Maria Sviatschi \\ Columbia University
}

\section{Discussion Paper No. 9502 \\ November 2015}

\author{
IZA \\ P.O. Box 7240 \\ 53072 Bonn \\ Germany \\ Phone: +49-228-3894-0 \\ Fax: +49-228-3894-180 \\ E-mail: iza@iza.org
}

Any opinions expressed here are those of the author(s) and not those of IZA. Research published in this series may include views on policy, but the institute itself takes no institutional policy positions. The IZA research network is committed to the IZA Guiding Principles of Research Integrity.

The Institute for the Study of Labor (IZA) in Bonn is a local and virtual international research center and a place of communication between science, politics and business. IZA is an independent nonprofit organization supported by Deutsche Post Foundation. The center is associated with the University of Bonn and offers a stimulating research environment through its international network, workshops and conferences, data service, project support, research visits and doctoral program. IZA engages in (i) original and internationally competitive research in all fields of labor economics, (ii) development of policy concepts, and (iii) dissemination of research results and concepts to the interested public.

IZA Discussion Papers often represent preliminary work and are circulated to encourage discussion. Citation of such a paper should account for its provisional character. A revised version may be available directly from the author. 
IZA Discussion Paper No. 9502

November 2015

\section{ABSTRACT \\ Bright Minds, Big Rent: Gentrification and the Rising Returns to Skill ${ }^{*}$}

In 1980 , housing prices in the main US cities rose with distance to the city center. By 2010 , that relationship had reversed. We propose that this development can be traced to greater labor supply of high-income households through reduced tolerance for commuting. In a tractlevel data set covering the 27 largest US cities, years 1980-2010, we employ a city-level Bartik demand shifter for skilled labor and find support for our hypothesis: full-time skilled workers favor proximity to the city center and their increased presence can account for the observed price changes, notably the rising price premium commanded by centrality.

JEL Classification: R21, R30

Keywords: gentrification, returns to skill, time use, location choice

Corresponding author:

Cecilia Machado

Getulio Vargas Foundation

Graduate School of Economics

Praia de Botafogo 190, 11th floor

Botafogo, Rio de Janeiro 22250-900

Brazil

E-mail: cecilia.machado@fgv.br

\footnotetext{
* We have benefitted from discussions with Joe Altonji, V. V. Chari, David Deming, Jonathan Fisher, Jonathan Heathcote, Matthew Kahn, Shirley Liu, Douglas Lucius, Chris Mayer, Enrico Moretti, Marcelo Moreira, Bernard Salanie, Aloysius Siow, Seminar participants at the Minneapolis Federal Reserve, the Barcelona Graduate Summer School 2015, The Econometric Society World Congress August 2015. We thank the New York Federal Statistical Research Data Centers, Baruch, Center for Economic Studies, U.S. Census Bureau. Any opinions and conclusions expressed herein are those of the authors and do not necessarily represent the views of the U.S. Census Bureau. All results have been reviewed to ensure that no confidential information is disclosed.
} 
I know things will get better

You'll find work and I'll get promoted

We'll move out of the shelter

Buy a bigger house and live in the suburbs

Tracy Chapman, Fast Car, 1988

The truth is that we are living at a moment in which the massive outward migration of the affluent that characterized the second half of the twentieth is coming to an end.

Ehrenhalt, The Great Inversion, 2013

\section{Introduction}

In 1980, US central-city residential real estate carried only a slight price premium. In fact, prices were higher beyond than within 10 miles of city centers. Fast forward 20 years and the center commands the highest prices, whence they fall sharply with distance for the first five miles and then flat lines. This pattern remains in 2010, unscathed by the 2007 housing market correction (Figure 1).

What lies behind this urban renewal, or "gentrification"? The literature has noted a number of signature features, such as depressed initial prices; and proximity to mass transportation and amenities [Kahn, 2007, Glaeser et al., 2008, 2012, Guerrieri et al., 2013].

Remains the question why centrality has increasingly come to be the local amenity. Gyourko et al. [2013] tied gentrification to a growing number of high-income households combined with inelastic housing supply, the case in city centers by necessity but also elsewhere courtesy of ordinances and the like [Ortalo-Magne and Prat, 2014]. However, the US economy grew at a healthy clip throughout the 1950s and 1960s, a time of urban decline and expansion of the suburbs [Jackson, 1985]. Granted, income growth was more evenly distributed, but the top 5 percent of earners have been increasing 
their share of income since the early-1950s and the top 1 percent since the mid-1960s [Kopczuk et al., 2008, figure 2B].

The premium on central location seems to reflect more than a filling-up of scarce space by high-income households. City-dwellers that ten, twenty years ago would have headed straight for the suburbs at the first sign of baby now stay put despite cramped living and high rents. ${ }^{1}$

This paper proposes that the roots of gentrification can be found in the shrinking leisure of high-income households. This time scarcity, we hypothesize, has propelled centrality to the top of the local amenities list.

Between 1965 and 2005, leisure grew but not for the college educated. In the 1985-2005 period, the contraction in leisure among college men was substantial enough to result in an overall reduction for men (leisure grew among non-college men); for women, leisure contracted across the board but at the twice the rate for college women compared to non-college women [Aguiar and Hurst, 2009, table 2-2].

Aguiar and Hurst [2007, 2009] identified rising labor supply of the skilled to lie at the core of this development. Census data bear this out. The fraction college graduates who worked full time started to rise in the 1970s after three decades of barely moving, Figures 2 and 3. Unsurprisingly, the increase was more pronounced for women. Since 1990, there has also been a notable increase in the fraction (men and women) working $50+$ hours per week (or "long hours" to use the terminology of Kuhn and Lozano $[2006])^{2}$

Long hours render non-work time scarce, planting low-utility activities such as commuting in the cross-hairs. One of the simplest ways to control commuting is to live close to work, which for skilled workers may mean the city center. There, by definition, land is scarce and higher demand translates into higher land rents. In time, local amenities adjust, boosting the attractiveness of the locality, further fueling the gentrification process. The core driver, however, we propose, can be found in the labor

\footnotetext{
${ }^{1}$ The October 232015 New York Times article "Growing Families That Stay Put" perhaps ironically gave "children" as the reasons for why New York City families choose to not move out of cramped apartments.

${ }^{2}$ Use of the Current Population Surveys (CPS) allows for finer education categories (but limits the time period). Distinguishing between just college and a graduate degree, the skill-hours gradient still holds. For men, the difference is particularly pronounced at the $50+$ hour margin, while for women it is evident also at the 40+ hour margin, Appendix Figures A1 and A2.
} 
market processes that have produced a corps of high-income-low-leisure individuals who live as singles or through assortative matching form dual-earner households.

Greater labor supply of the skilled is plausibly related to rising returns to skill [Katz and Murphy, 1992, Juhn et al., 1993, Autor et al., 2008], a development linked to the arrival of microprocessors in the early 1970s [Greenwood and Jovanovic, 1999, Hobijn and Jovanovic, 2001]. The ensuing Information Technology Revolution has been a boon to skilled employment growth in cities that were initially skilled [Berry and Glaeser, 2005, Moretti, 2013], a path dependency consistent with rapid technological change [Beaudry et al., 2010].

Like a number of recent papers, e.g., Diamond [Forthcoming], Moretti [2013], we will use college-employment demand shifters in combination with the 1970 city-level industry structure to generate an arguably exogenous, city-level, skilled labor demand shifter. The so called Bartik demand shifter helps us isolate our proposed labor-market driven explanation from alternative explanations. For instance, high-income households may always have valued central city living but in the past they were deterred by racial antagonism or high crime [Glaeser et al., 2001]. Another possibility is reverse causality, higher rents prod households to supply more labor [Johnson, 2012]).

Our hypothesis concerns the within-city distance-gradient of housing prices and our empirical analysis will be performed at the tract level. To create create tract-level variation we interact the city-level Bartik measure with the tract's (population weighted centroid) distance to the city center. In other words, we allow the city-specific demand growth to propagate differentially according to the tract's distance to the center.

Our main data set is a tract-level data set constructed from restricted-use US Census micro-data covering the period 1980-2010. We use tract geocodes to calculate (centroid) distance to a point in the central business district, and we will refer to this point as the CBD. Geographically, we limit our sample to cities that were in the top-20 (population

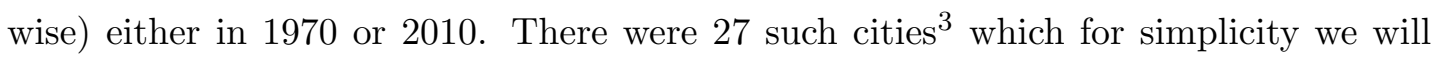
refer to as "top-20." We include tracts within 35 miles of the CBD regardless of whether

\footnotetext{
${ }^{3}$ They are: Austin, Baltimore, Boston, Charlotte, Chicago, Cleveland, Columbus, Dallas, Detroit, El Paso, Fort Worth, Houston, Indianapolis, Jacksonville, Los Angeles, Memphis, Milwaukee, New Orleans, New York, Philadelphia, Phoenix, San Antonio, San Diego, San Francisco, San Jose, St. Louis and Washington DC. Their respective center points are detailed in Appendix Table A2.
} 
they were in the same same city (or state) as the CBD. For the purpose of this paper, the terms cities or metropolitan areas will be used interchangeably to refer to these geographic entities.

To capture the rise of the high-income-low-leisure demographic, we focus on fulltime workers with a college degree among ages 25 to 55 . This age group was chosen to capture prime working ages, the years after college completion but before retirement concerns. These ages are also key home buying ages. ${ }^{4}$

Throughout, we will control for a battery of fixed effects. Our preferred specification has city-year fixed effects and city-specific distance controls. City-year fixed effects absorbs any city-wide changes, including city-level labor demand shifts or credit expansion (for a recent paper on the role of the latter, see Favara and Imbs [2015]). City-specific distance controls stand in for tract fixed effects (but we will see that our findings hold in a constructed tract panel data set that allows for tract fixed effects).

Allowing the Bartik demand shifter to have a differential impact on tracts 0-3 miles, 3-10 miles, 10-20 miles or 20-35 miles from the CBD we find the effect to be concentrated near the center: almost three times stronger in the 0-3 mile core compared to the contiguous 3-10 mile ring and almost seven times stronger than in the more distant 10-20 mile ring (the 20-35 mile ring served as the reference area). The implied price changes from the reduced form estimates replicate very closely the actual level and distance gradient of housing price increases.

First stage regressions reveal a strong relationship between full-time skilled workers and the Bartik demand shifter. The relationship is strongest close to the CBD, and then attenuates, the exact shape of the decline varying somewhat with the set of fixed effects.

Turning to the relationship between full-time skilled workers and housing prices, we find empirical support both in OLS regression analysis and in instrumented results using the Bartik demand shifters. Full-time skilled workers not only chose to locate close to the CBD, their presence there has a positive impact on prices. The implied price changes from the IV analysis suggest that the growth of full-time skilled workers can capture the 1980-2010 housing price changes (Figures 11-12).

\footnotetext{
${ }^{4}$ National Association of Realtors [2014].
} 
Some of the cities with the steepest price increases have also seen the largest declines in crime, New York City being a case in point with crime levels down by two-thirds from their late-1980s levels. To investigate the role of improved public safety, we split our cities into two equal sized groups, one with cities that saw large declines in crime and one with cities that saw modest declines or increases over the 1985-2012 period. ${ }^{5}$ Qualitatively, results hold in both groups. Quantitatively, the effects were also similar when fulltime was measured at 50 hours, but at the weaker measure of 40 hours, the high-decline cities saw a stronger effect than the low-decline cities. As a last robustness check, we cross walk tracts to create a tract-level panel data set, allowing us to include tract fixed effects, an inclusion that yields results similar to those obtained using city-distance fixed effects. Further, we split tracts according to their percent black population in 1980 (above or below the 1980 median) and find results to be similar in the two samples, suggesting that the found results are not predicated on a particular racial composition.

Finally, Census data allow us check our premise that skilled jobs are disproportionately located in the central city, and we confirm this to be the case. Unskilled jobs, on the other hand, are more dispersed and increasingly so. As a corollary, we expect commuting time, especially for the skilled, to increase with residence distance to the central city. We find that to be the case for men throughout the studied period and increasingly also for women, consistent with the latter's greater labor force attachment.

The remainder of the paper is organized as follows. Section 2 gives further background and literature review. Section 3 describes our empirical strategy and data set. Section 4 presents the descriptives and results. Section 5 concludes.

\section{Background and Existing Literature}

This paper's hypothesis turns on the increasing hours worked by high-income households, which, to paraphrase Ehrenhalt [2013], has given rise to an affluent class who treat leisure as their most prized commodity.

\footnotetext{
${ }^{5}$ The years for which crime statistics are readily available. http://www.ucrdatatool.gov/Search/ Crime/Local/TrendsInOneVarLarge.cfm
} 
Individual v. Household Labor Supply We have chosen to focus on individual rather than household labor supply. Obviously, labor supply is a household decision. However, the trends in household formation and labor supply behavior mean that the distinction between individual and household labor supply behavior is fading.

First, there are more single headed households also among the skilled. While the skilled tend to marry, they do so later. The median age of first marriage among college educated was 28 in 2008, up from 23 in 1970; an additional five cohorts of college educated singles. ${ }^{6}$

Second, among couples, the cross-wage elasticity of women's labor supply is shrinking [Heim, 2007]. That is, married women are increasingly behaving as if they were single. Later marriage and higher risk of divorce [Edlund and Pande, 2002, Fernndez and Wong, 2014] have reduced the economic value of marriage to women pushing women into the labor force. Rising returns to skill figure prominently among pull factors.

As skilled women have become more attractive on the labor market, their currency on the marriage market has also appreciated, at least that is one reading of the greater degree of positive assortative mating evident in US data [Greenwood et al., 2014]. Positive assortative mating can boost married women's labor supply since the women who can most afford to stay home are also the ones leaving the most money on the table.

In other words, the increase in women's labor supply is mainly driven by married women, e.g., Juhn and Murphy [1997], DiCecio et al. [2008], McGrattan and Rogerson [2008], Schwartz [2010]. Married women's working has given rise to more dual-earner households. Although high-income dual-earner households are part of the demographic change we hypothesize have fed gentrification, the rise in high-income dual-earner households is one that is captured by the rise in skilled individuals' labor supply. High-income dual-earner households have interesting implications for the types of apartments in demand (larger) and amenities sought after (family friendly?) and thus bears on urban development. However, as far as housing prices are concerned, their impact may be captured by individual-level measures of labor supply.

\footnotetext{
${ }^{6}$ http://www . pewsocialtrends .org/2010/10/07/the-reversal-of-the-college-marriage-gap/
} 
Drive 'Til You Qualify Our paper is in the spirit of what Mieszkowski and Mills [1993] called the "natural evolution theory of urban development" augmented with labor supply and household commuting decisions [White, 1977, Madden and White, 1980, Madden, 1980]. Rappaport [2014] explicitly considered utility from leisure, thereby sharpening the attention on commuting time. Empirically, his study made the case for the relevance of the monocentric city model for mid-sized US cities, focusing on Portland, Oregon.

While our paper stresses labor market changes, it is also quite possible that commuting itself has become onerous. On average, travel time for workers in the US increased by 20 percent between 1980 and 2009, or eight minutes per day [McKenzie and Rapino, 2011].

Rail transportation avoids traffic congestion, and can be combined with working. Interestingly, Kahn [2007] found proximity to "walk-and-ride" stations to be particularly conducive to gentrification in his 14-city study using tract level panel data.

Centrality and Other Amenities Jacobs [1961] drew attention to the economies of scale and scope offered by the city center and their importance for human capital intensive activities. Positive externalities in the "knowledge economy" create centrality and thus land scarcity around central points. Restriction on construction and the durable nature of real estate further contributes to steepen the housing supply curve in the center.

Davis and Heathcote [2007] decomposed housing prices into two components, the replacement cost of the structure and the land rent. They found that since the 1950s, residential land prices have grown at twice the rate of per capita income and (because of its low supply elasticity compared to structures) can account for most of the variation in housing prices; findings consistent with demand for residential real estate being increasingly center focused.

Thus semi-fixed supply of housing and non-zero transportation time link the housing market to the labor market. As wages have seen increased dispersion, so have housing prices [Van Nieuwerburgh and Weill, 2010]. Further, the increase in the wage dispersion has been driven by the right tail, which can lead to runaway price growth 
in areas with particularly inelastic housing supply, viz. city centers [Gyourko et al., 2013]. A difference with Gyourko et al. [2013] however, is our focus on the importance of centrality. In other words, our hypothesis does not predict "superstar" suburbs.

Rents tend to be higher in high-wage cities, a fact that compresses real-wage inequality [Moretti, 2013]; although the possibilities of better amenities (including more skill building jobs [Glaeser and Mare, 2001], better partner search or co-location possibilities [Costa and Kahn, 2000, Compton and Pollak, 2007]) work in the opposite direction. Diamond [Forthcoming] quantified these effects by estimating a structural model of endogenous location choice and amenities.

While the prototypical gentrified neighborhood was wanting in most amenities save centrality, e.g., McDonald [1986], centrality is clearly not the sole amenity of importance. Guerrieri et al. [2012, 2013]'s model of gentrification turned on proximity to rich neighborhoods. As a city experience a positive labor demand shock, poor neighborhoods close to rich neighborhoods gentrify. Conversely, a negative labor demand shock (viz. Detroit) leads to a de-gentrification of marginal neighborhoods (those in between rich and poor neighborhoods). The proposed project complements this narrative by tying ground-zero to commuting time. Further, the suburbanization of the 1960s, a time of growing affluence, pose a challenge to Guerrieri et al. [2012, 2013] but is consistent with ours (female labor-force participation among high-income households was low in that period, rendering suburban residence ideal).

Monocentricity need not be based on concentration of economic activity. The city center could be thus because of public sector administration, educational or cultural institutions. Cities have seen a revival in Europe as well and in a recent paper SaintPaul [2015] argued that gentrification can be tied to the knowledge economy which has moved skilled jobs to the city center.

Families and Public Schools During the study period, several policies aimed at facilitating school choice (and quality) such as charter schools and vouchers were introduced, which may have helped tip the balance in favor of city location.

However, one reason school quality may be secondary for gentrification is the high land rents in the central city. This cost disadvantage combined with the unfavor- 
able dependency ratio of families with young children suggest that the city would be unattractive to large families. In other words, the childlessness that characterized early gentrifiers (e.g. yuppies or gays [Black et al., 2002]) may continue to dominate gentrification, quite independently of the quality of public schools. ${ }^{7}$

Another reason is that public school quality may be endogenous to the local demographics.

One way for us to examine the importance of public school quality is to study the age distribution. To preview results, we find that the CBD is no country for the young. These statistics suggest a limited role of the quality of public schools in gentrification.

Crime A local amenity of particular interest is crime. Violent crime rose between 1960 and 1990, and then declined. ${ }^{8}$

Does the decline in crime confound our explanation of gentrification? Clearly, the reduction in lawlessness has made US cities immeasurably more livable. On the other hand, from gentrification alone we would expect a reduction in crime, both because of a less crime prone demographic and higher demand for law and order; Diamond [Forthcoming] found that greater city level demand for skilled labor reduced crime.

We also note that European cities did not experience a level or concentration of crime in the inner cities anywhere near that of the US in the 1970s or 1980s but have experienced similar, core-centered, urban renewal, e.g., Carpenter and Lees [1995], Boterman et al. [2010], Saint-Paul [2015].

Still, the crime question is hard to ignore. To somewhat address this question we split our sample cities into two groups according to whether above or below the (population weighted) median crime reduction over the 1985-2012 period. To anticipate results, our main findings hold in both samples (Table 8).

\footnotetext{
${ }^{7}$ Incidentally, in a survey of home buyers, quality of schools came in only 5th among factors influencing neighborhood choice, after quality of neighborhood; convenient to job; overall affordability; convenient to friends/family [National Association of Realtors, 2014, exhibit 2-7, emphasis added].

${ }^{8}$ The origins of its rise and fall are debated. A non-exhaustive list includes the removal of school prayers, abortion legalization [Donohue and Levitt, 2001, Foote and Goetz, 2008], more aggressive and targeted policing, greater incarceration rates, electronic surveillance, ATMs and credit cards, the crack epidemic, and environmental factors such as lead exposure [Reyes, 2007].
} 
Race Residential location patterns in the recent past have evidenced a high degree of taste for racial segregation, especially along the white-black demarcation line [Schelling, 1969, Cutler et al., 1999, Card et al., 2008]. Card et al. [2008] documented thresholds for minorities beyond which white flight took place, so called tipping points, and Aaronson [2001] found high racial persistence. This literature suggests that gentrification may be slower in areas with a large initial black population. Therefore, we construct a panel data set and split tracts by their 1980-level percentage black. We find similar results in the two samples (Table 8), suggesting that our proposed mechanism is not predicated on any particular racial composition.

\section{$3 \quad$ Data and Empirical Strategy}

Our primary data set is drawn from the decennial censuses of 1980, 1990 and 2000, and the American Community Survey (ACS) pooled 2008-2012 sample (which offers sufficient sample size). The chosen level of aggregation is the census tract. The Census writes: "Census tracts generally have a population size between 1,200 and 8,000 people, with an optimum size of 4,000 people." ${ }^{9}$ For each tract, we aggregate individual- or household-level information and calculate the distance to the city center (by matching the tract to its centroid latitude and longitude).

Measures of housing prices are generated using self-reported estimates for owneroccupied single-family homes with two or three bedrooms. We use households no more than ten years in the current residence on the assumption that owners of more recently transacted units would be more knowledgeable about going market price. ${ }^{10}$ The restriction to two- or three-bedroom single-family homes was done in order to obtain a price that refers to comparable units while preserving sample size.

We focus on ages 25-55, ages often used delineate the prime-age population.

Further details on data set and variable construction are in the Data Appendix.

\footnotetext{
${ }^{9}$ http://www.census.gov/geo/reference/gtc/gtc_ct.html

${ }^{10}$ Including all households yield similar results.
} 


\subsection{Cities}

We focused on the 27 cities which were in the top-20 either in 1970 or 2010 . The list is topped by New York City in both years and the number 20 spot is taken by Phoenix and Memphis in 1970 and 2010 respectively.

We limit our sample to tracts within 35 miles of the city center point or "CBD" (detailed in Table A2). This restriction is arbitrary but arguably delineates a commutable area, the outer reaches of which would be about an hour away from the center For our city sample and the years 1980, 1990, 2000 and 2010, we have about 65 thousand tract-year observations, or an average of 600 tracts per city and year. ${ }^{11}$

For details on how city centers were picked, please see the Appendix.

\subsection{Bartik demand shifter}

We used the public use version of the decennial censuses (IPUMS) to calculate the city-specific demand shifter for skilled employment from the national growth rates of employment of college workers in industry $h$, excluding the city in question, $-j$, weighted by each industry's employment share in city $j$ in 1970. The base year 1970 was chosen because the IT revolution and the rise in wage inequality (returns to skill) date to the ensuing decade [Beaudry et al., 2010].

Specifically, focusing on ages 25-55, we construct our Bartik demand shifter for skilled labor demand for city $j$ and year $t$ as:

$$
Z_{j t}=\frac{1}{N_{j, 1970}} \sum_{h}^{41} n_{h, j, 1970} \times\left(\ln n_{h,-j, t}-\ln n_{h,-j, 1970}\right),
$$

where

$N_{j, t}$ is the number of workers in city $j$ and year $t=1980,1990,2000,2010$,

$n_{h, j, t}$ is the number of college educated workers in industry $h$, city $j$, year $t$,

$n_{h,-j, t}$ is the number of college workers in industry $h$ and year $t$, excluding city $j$. In words, the first factor is the 1970 city specific industry share in 1970; the second factor is the logged national growth, excluding city $j$, for that industry in terms of college

\footnotetext{
${ }^{11}$ For disclosure reasons, the sample size is rounded.
} 
workers. Thus, $Z_{j t}$ can be interpreted as the share of employment in city $j$ predicted to be held by college educated workers.

Throughout the studied period, $Z_{j t}$ is book-ended by San Antonio and Washington DC. In 1980, San Antonio had a predicted share of college educated workers of 9 percent compared with DC's 23 percent. Thirty years later, 2010, those numbers were 18 and 46 percent respectively.

The Bartik measure is city specific and detailed in Table A2. ${ }^{12}$ We allow the cityspecific demand shifter to propagate differentially through the city by interacting it with a function of distance to the city-center. We expect the demand shift to operate more strongly close to the CBD, where jobs are concentrated (an assumption we will confirm) and decline thence.

\section{Analysis}

We start by presenting descriptive statistics (means) for each year by distance categories 0-3, 3-10, 10-20, and 20-35 miles from the CBD, and in a series of graphs showing smoothed polynomials based on 1-mile distance intervals. We will employ the following notation: BA- for less than four-year college, BA for at least four-year college but no advanced degree, $\mathrm{MA}+$ for advanced degree, and $\mathrm{BA}+$ for $\mathrm{BA}$ and $\mathrm{MA}+$.

House prices Between 1980 and 2010, housing prices in the top-20 cities rose by 30 percent from 92.5 to 120.5 thousand 1980 constant dollars for a two-or-three bedroom one-family home. Turning to price changes by distance to the CBD and we see that price increases were higher in more centrally located tracts. In the core (0-3 miles), prices more than doubled. In tracts 3-10 miles out, prices rose by 60 percent, whereas price increases were a mere 10 and 6 percent in tracts $10-20$ and 20-35 miles out, respectively. In fact, the price profile flips. In 1980, prices in the periphery are 50 percent higher than in the center. By 2010, prices in the center are 40 percent higher than in the periphery, Table 1 and Figure 1.

\footnotetext{
${ }^{12}$ Except Dallas-Fort Worth, coded as one city in the IPUMS.
} 
Full-time skilled workers We let $F T(h, e)$ denote the fraction of adults 25-55 who worked more that $h, h=40,50$ hours per week and had education $e, e=B A+, M A+$.

The fraction of adults 25-55 who worked full-time and had college degree increased in our top-20 cities throughout the period, a development driven by women, Table 1 and Figures 4 and $5 .^{13}$

As for location, in 1980, $F T(40, B A+)$ rose with distance to the city center, while $F T(40, M A+)$ declined slightly. In 2010, the population in the center was significantly higher in the city center than the periphery, by 24 and 50 percent for $F T(40, B A+)$ $F T(40, M A+)$ respectively. The growing proclivity to favor the city center is even more pronounced among those working long $(50+)$ hours, Table $1 .{ }^{14}$

Breaking down residence location by gender, we see that BA men working full time were more likely to live away from the center than either skilled women or MA+ men, Figures 4 and 5.

Location of jobs, distance to the CBD To investigate our premise that the skilled work in the city center, we graph the distribution of jobs held by adults 25-55 (not conditional on hours) by the education level of the worker, Figure 6. We see that all jobs are concentrated in the city core, but more so for the skilled than the unskilled. Further, while there has been a "suburbanization" of jobs, it is particularly pronounced for the unskilled: unskilled jobs decreased within 7 miles of the city center and grew outside of that ring. Skilled jobs grew throughout.

Commuting time Average time spent commuting rose by 15 percent over the study period [McKenzie and Rapino, 2011, figur 3]. Urban sprawl may be a factor. However, as Figures 7-8 show, commuting time for workers at any given distance to the CBD has increased, and the increase is in the range seen for the nation as a whole.

Turning to commuting patterns by distance to the CBD, we see that the BA+ group spend more time commuting than the BA- group, suggestive of the importance of skill match and concentration of skilled jobs in the CBD, Figure 9. Men spend more time commuting than women, but the difference narrowed over the period. The greatest

\footnotetext{
${ }^{13}$ Also true nationally for MA+ women working $40+$ hours, see Appendix Table A1.

${ }^{14}$ Meanwhile, unskilled full-time workers moved away from the center, Figure A3.
} 
increase in commuting time is seen for BA women living at the outskirts. In 1980, they seem to work locally, whereas by 2010 the catchment area appears to have widened, consistent with a greater weight given to the skill match, Figure 8 .

Age composition We now turn to the age distribution by distance. We find that although urban revival has been tied to hipsters and empty nesters, the prime age population dominates the city core, a tendency that increased over the study period, Figure 10. In 1980, their share of the population was j-shaped, bottoming out around 4 miles from the CBD. In 2010, the $\mathrm{j}$ had fallen on its back - the share decreased monotonically with distance, the sharpest decline being within the first five miles of the CBD.

While young adults, 19 to 24 years old, have long favored the central city, their presence decreased over the study period. Thus, this demographic does not seem to be a prime driver of gentrification, perhaps not surprising considering their limited purchasing power compared to the 25-55 age group.

As for ages 56 and above, this group has increased its presence in the population overall but the growth in this demographic is concentrated 10 miles out of the CBD. Within 10 miles of the CBD, there is a decrease. This was true of both the 56-65, and the $66+$ population, Table 1 .

As regards children 0 to 18 years old, their share has declined nationally and in our sample. The declined is particularly pronounced close to the city center, suggestive of a limited role for the quality of public schools in shaping gentrification.

Turning to the fraction children in private school and we find that a higher fraction of children attend private school in tracts close to the CBD and there was an increased between 1990 and 2000, but declined between 2000 and 2010 (Figures A4-A5). Two countervailing forces are likely at play. From a more affluent demographic close to the CBD we would expect a higher fraction of children attending private schools. On the other hand, the same demographic changes likely result in improved public schools.

The most striking change, however, is the erosion of the hump in private school enrollment about 10 miles out of from the CBD evident in 1980. Since there are few reasons to believe suburban public schools improved over the period, this change likely 
reflects a poorer suburban demographics.

Other demographics Table 1 also report tract means for income (total personal, $1980 \$)$, percent non-Hispanic white, black, and married. Over the period, income rose by 25 percent, and as expected the gains were concentrated in tracts close to to the CBD. In the 0-3 mile core, income rose by almost 80 percent.

The percent non-Hispanic white declined by 12 percentage points for our sample, whereas the percent blacks increased only slightly (from 19.4 to 19.6 percent). In the central city, however, the pattern was reversed: percent black declined while percent non-Hispanic white held steady. As for marital status, marriage decline during the study period, and in percentage terms the decline was steeper within 10 miles of the city center (25 v. 15 percent).

\subsection{Regression Analysis}

Reduced form We start by investigating the reduced form effect of a demand shock on housing prices by estimating the following regression:

$$
P R I C E_{i j t}=Z_{j t}+f\left(d i s t_{i j}\right) Z_{j t}+f\left(d i s t_{i j}\right)+\alpha_{j}+\alpha_{t}+\epsilon_{i j t}
$$

where $P R I C E_{i j t}$ is the housing price in tract $i$ in city $j$ and year $t, Z_{j t}$ is the exogenous labor demand shock in city $j$ in year $t$ (cf. Equation 1 ) and $f\left(\right.$ dist $\left._{i j}\right)$ is a flexible function of $d i s t_{i j}$, the tract distance in miles to the CBD. The regression also includes year and city fixed effects, $\alpha_{t}$ and $\alpha_{j}$, or, alternatively, city-year fixed effects, $\alpha_{j t}$. We control

for distance specific characteristics through $f\left(\right.$ dist $\left._{i j}\right)$ and allow for distance differential impacts of $Z_{j t}$ through $f\left(d i s t_{i j}\right) \times Z_{j t}$. Throughout, standard errors are clustered at the city level, and tracts are weighted by their population size.

Table 2 presents the results. The first column shows the results from a bare-bones version of Equation 2, where

$$
f\left(d_{i s t_{i j}}\right)=d 1_{i j}+d 2_{i j}+d 3_{i j}
$$

where $d 1_{i j}, d 2_{i j}$, and $d 3_{i j}$ are three distance indicator variables for the 0-3 mile core, 
the 3-10 mile radius ring, and the 10-20 mile ring respectively. (The 20-35 mile ring is the reference area.)

We see that the effect of demand for skilled labor as measured by the $Z_{j t}$ instrument is stronger close to the $\mathrm{CBD}$, the estimated impact being 2.5 times larger in the core than 3-10 miles out (588.9/234.5), and 6.7 times larger than in the 10-20 mile ring $(588.9 / 88.25)$.

Between 1980-2010, $Z$ increased by about 13 percentage points, ${ }^{15}$ implying house price changes of 75, 29 and 11 thousand 1980 USD in the 0-3 mile core, 3-10 mile, and 10-20 mile rings respectively (relative to the 20-35 mile ring). The predicted price changes line up closely with the observed price changes of 82, 30 and 4.5 thousand 1980 USD, respectively.

Results remain virtually unchanged when adding city-year fixed effects (column 2), indicating common price responses to demand for skilled labor for the cities in our sample over the study period.

Columns 3 and 4 us a quadratic or cubic specifications for $f\left(\right.$ dist $\left._{i j}\right)$. While more parametric, these polynomials capture a similar effect of the demand shock: positive but fading with distance.

Ideally, we would like to control for tract fixed effects but tracts change between the censuses. We will construct a tract panel data set using cross-walk files but the fidelity to the underlying tract characteristics is lower and therefore we favor results from the repeated cross sectional sample. ${ }^{16}$ As a step towards tract fixed effects, we add vector of city-specific distance fixed effects $g\left(\right.$ dist $\left._{i j}\right)$ to Equation 2, that is, for columns 5-8 we estimate

$$
P R I C E_{i j t}=Z_{j t}+f\left(d i s t_{i j}\right) Z_{j t}+f\left(d i s t_{i j}\right)+g\left(d i s t_{i j}\right)+\alpha_{j}+\alpha_{t}+\epsilon_{i j t},
$$

\footnotetext{
${ }^{15}$ Table A2

${ }^{16}$ Results were similar in the constructed tract panel data set and the cross sectional sample, see Tables 6 and 8 .
} 
where for each city $j$ we let:

$$
g\left(d i s t_{i j}\right)=\sum_{k=1}^{21} \beta_{k j} d k_{i j}
$$

where $d 1-d 20$ are indicator variables for the tract being $[0,1),[1,2), \ldots,[19-20)$ miles away from the CBD ( $d 21$ indicates distance in the [20-35) mile range).

Results remain similar with this inclusion of "ring fixed effects," columns 5-8.

First stage - T1st Table 3 , shows the direct effect of $Z_{j t}$ on $F T(h, e)_{i j t}$ - the fraction adults 25-55 in tract $i$, city $j$, year $t$ who worked more that $h=40,50$ hours per week and had education $e=B A+, M A+$. We estimate a variant of Equation 2 where $f(\cdot)$ is given by Equation 3 and the following three, successively more demanding, sets of fixed effects: (1) city-year fixed effects; (2) city-distance fixed effects and year fixed effects; and (3) city-distance fixed effects and city-year fixed effects.

Columns 1-3, upper panel, show the results for $F T(40, B A+)$. We see a strong positive effect of $Z$ close to the CBD. The magnitude is reduced once city-specific distance fixed effects are included (columns 2-3), but the qualitative flavor remains. The point estimate from the third specification says that a 0.10 increase in $Z$ leads to a 3.3 percentage point higher increase in $F T(40, B A+)$ in tracts $0-3$ miles within the CBD compared to tracts 20-35 miles out.

The results from the three other full-time measures are qualitatively similar results.

We now turn to other demographics that may change with the Bartik demand shifter and plausibly influence housing prices. We estimate the same set of specifications as in Table 3 but substitute the percent black, married, and personal income for the full-time measure as the dependent variable.

Since these variables are correlated with the educational and employment status of the population we expect to find a relationship. The reason we favor $F T(\cdot)$ over these other variables is the direct causal link from growth in a skill intensive industry to a more skilled and employed population. We view other demographic changes to be incidental or derived from the primary relationship. Be that as it may, Table 4 presents the results for these other demographics. 
Starting with the percent black, we see that in the first specification (including city-year fixed effects but not city-distance fixed effects), a higher Bartik reduces the fraction blacks in tracts close to the city center. Adding city-distance fixed effects (specifications two and three) halves the effect size but leaves the qualitative result unchanged, Table 3, Columns 1-3.

Turning to non-Hispanic whites, we see a pronounced positive effect of the Bartik demand shifter close to the CBD, Columns 4-6.

As for the percent married, in the first specification, we find no significant effect of the Bartik demand shifter, Column 1, lower panel. Adding city-distance controls, we find a small positive effect close to the CBD and a reduction in tracts 3-20 miles out, Columns 2-3, lower panel.

Lastly, for personal income the estimated relationship is u-shaped with respect to distance, with a trough in the 3-10 mile interval, Columns 4-6, lower panel.

OLS We can now engage our hypothesis that the emergence of centrality as a top amenity is linked to high-income households being time starved. We focus on our preferred specification which controls for city-year and city-specific distance fixed effects:

$$
P R I C E_{i j t}=F T(h, e)_{i j t}+f\left(d_{i s t} t_{i j}\right) F T(h, e)_{i j t}+g\left(d i s t_{i j}\right)+\alpha_{j t}+\epsilon_{i j t},
$$

where as before $f\left(d_{i s t_{i j}}\right)$ allows for the effect of $F T(h, e)_{i j t}$ to vary with tract distance to the CBD, and $g\left(d_{i s t}\right)$ is as in Equation 5.

We present three variations on Equation 6: (1) $f\left(\right.$ dist $\left._{i j}\right) F T(h, e)_{i j t}$ is omitted; (2) $f(\cdot)=$ dist $_{i j}$; and (3) $f(\cdot)=d_{i s t_{i j}}+d i s t_{i j}^{2}$. The OLS results from these three specifications estimated for our four full-time measures are presented in Table 5 . We see that that the fraction full-time skilled workers in the tract and the tract's housing prices are positively related and the effect fades with distance to the CBD.

There are many reasons to question the interpretation of these OLS results, however. Higher housing prices could prompt greater labor supply or the association could be spurious. The central city could have been more attractive to the high-skill-low-leisure population for reasons unrelated to commuting. Their presence could be driven by the cultural amenities on offer in the city center or simply be part of a zeitgeist in 
which an urban aesthetics is embraced perhaps as a reaction against subdivisions and cul-de-sacs.

IV We now turn to our IV estimates where we instrument our full-time skilled worker measure by the Bartik demand shifter described in Section 3.2. Our identifying assumption is that the Bartik demand shifter affects housing prices only through the posited channel of raising the fraction of the population that is skilled and works full time. The effect could stem directly from the purchasing power of a skilled, steadily employed population, or may be through the mores and preferences of this segment (e.g., regarding issues such as policing, liquor permits, bike lanes, etc.).

More worrying would be if demand growth for skilled labor affected other dimensions that in turn moved housing prices. For instance, a higher Bartik may result in higher tax revenues which in turn allow for better policing, infrastructure, or civic initiatives that improve quality of life, and possibly more so close to the city center.

Pure racism presents another challenge. Consider the case of tipping points. It is possible that a higher Bartik changes the demographics of a tract enough to make it tip. For instance, prices in a centrally located tract may be low because its high proportion blacks deters whites. As centrality gains salience, more whites move in, eventually bringing the proportion blacks below the tipping point. Thence, white reservation vanishes and prices take off. Note, however, that for the outlined mechanisms to be a threat to our identification strategy, we need pure racism. Racial stereotypes that merely reflect generalities regarding the behavior and preferences of a group based on their education level, income, or employment status do not suffice.

With these caveats in mind, we now turn to our findings from estimating Equation 6 where $F T(h, e)_{i j t}$ and $f\left(d i s t_{i j}\right) F T(h, e)_{i j t}$ are instrumented by $Z_{j t}\left(1+d 1_{i j}+d 2_{i j}+\right.$ $\left.d 3_{i j}\right)$. As in the case of the OLS regressions, we present three specifications: (1) $f\left(d_{i s t_{i j}}\right) F T(h, e)_{i j t}$ is omitted; (2) $f(\cdot)=d_{i s t_{i j}}$; and (3) $f(\cdot)=d_{i s t_{i j}}+d i s t_{i j}^{2}$.

Throughout, the rudimentary specification in which $F T(\cdot)$ is hypothesized to have a uniform effect on housing prices regardless of distance to the CBD (and thus land availability) fails the over-identification test (JP) and therefore we focus on specifica- 
tions two and three. ${ }^{17}$ Both specifications estimate a positive effect of the fraction of full-time skilled workers among the prime-age population (statistically significant at the 0.1 percent level), and the effect is more pronounced closer to the CBD.

To gauge the economic significance of our proposed explanation for gentrification, Figures 11 and 12 show the predicted housing price increases for the linear and square specifications respectively. We see that both specification do a good job replicating the actual price changes.

Robustness We now show the results from estimating the second specification in a series of alternative samples as a robustness test (the first specification fails the overidentification test, the third specification gives very similar results as the second but the added interaction with distance squared is insignificant at conventional levels).

Motivated by the significant reduction in crime over the study period, we split the cities according to the decline in crime (see Table A1). It is reassuring that our results go through in both samples, although the strength of the first stage is somewhat weakened. For the $40+$ full-time measures, the effect size is noticeably smaller in the low (crime reduction) sample, whereas for the $50+$ full-time measures, the estimated coefficients are similar in the two samples, Table 8, Columns 1 and 2 samples.

New York City is the largest US city, and may be exceptional in other ways too, be it from the particularities forced geography, Manhattan Island in particular, the concentration of the finance industry, the substantive presence of foreign buyers, or the fact that it has a midtown and a downtown center. In order to gauge the extent to which our results are driven by the presence of New York City, Column 3 presents results from a sample where it has been excluded. Again, the results for the $50+$ hours full-time measures are very similar to those of the whole sample, while the estimated effect size for our $40+$ hours measure is reduced in magnitude (but remains statistically very significant).

In the last three columns we present results from a tract panel data set constructed using cross walk files from US2010. ${ }^{18}$ The thus constructed tracts, however, reflect the

\footnotetext{
${ }^{17}$ The p-value of the Kleibergen-Paap LM test is below $1.7 \%$ throughout, rejecting the null that the model is underidentified.

${ }^{18}$ http://www.s4.brown.edu/us2010/Researcher/Bridging.htm
} 
underlying demographics with less fidelity (for further details, see the Appendix).

Column 4 presents results from including tract fixed effects and we find results to be quite similar to the cross sectional sample (suggesting that the city-specific distance fixed effects are passable substitutes for tract fixed effects).

Our main interest in a tract-level panel data set derives from the possibility that initial conditions (other than distance) influence gentrification. In particular, we are interested in the role of the initial racial composition of the tract.

To that end, we divide our panel data set according to whether the (constructed) tract was above or below the median in terms of percent black in 1980 (the mean and median values were 18.7 and 2.5 percent respectively, reflecting a high degree of residential segregation).

We find results to be very similar in the two samples, Columns 5 and 6 . That is, once tract fixed effects and city-year fixed effects are controlled for, the effect of fulltime skilled workers on housing prices are estimated to be similar in tracts that had few blacks (below 2.5 percent) and tracts that had a high fraction blacks (the implied mean being close to 40 percent).

\section{Discussion}

For most of the 20th Century, suburbanization dominated the US urban landscape. However, as the century drew to a close it was clear that a counter movement was afoot. Today, gentrification has grown out of its erstwhile niche status to epitomize a broad based rehabilitation of the central city as the place to work, live, and play.

The driving factor, we have proposed, can be found in a growing corps of highincome-low-leisure households who by virtue of being time starved seek to locate close to work. Thus, our paper adds urban renewal to the list of time-saving machinations of modern life.

The ideas collated in this paper are by no means new. They hew closely to the canonical models of urban development, and labor supply. The employment of a Bartik demand shifter also follows a well-beaten path. To the best of our knowledge, however, ours is the first paper to emphasize the time scarcity of high-income households as the 
explanation for the reversal of suburbanization and to present comprehensive empirical evidence to that effect.

We have focused on individual labor supply and lumped men and women together. In the preliminary analysis we looked at men and women separately and found them to yield similar results, possibly because the expansion of hours have been qualitatively similar for skilled men and women. It is conceivable, however, that had the ever harder working skilled men been paired with full time housewives, the situation would have been wholly different.

The Suburbs Are Dead - Long Live the Suburbs Gentrification is about price growth and changes to the housing stock, not population growth. Plenty of people will find enduring value in the affordability and leafiness of the suburbs. However, other aspects of suburban life may change.

For instance, between 2000 and 2010, Manhattan and Brooklyn poverty rates declined by 10 percent, but rose on Staten Island (the most suburban of New York City's five boroughs). ${ }^{19}$ While more notable recently, poverty has been rising faster in suburbs than cities since the 1980s [Kneebone and Berube, 2013].

To its critics, gentrification signifies the displacement of lower income households. As the term suggests, displaced people show up somewhere else. The inner city, even at its nadir, always had centrality going for it [Glaeser et al., 2000]. How do low-wage workers, single-parents in particular, manage in suburban locations, areas built with car ownership in mind and targeted to middle-class families with a stay-at-home wife?

Beyond the Burbs A topic of less social urgency but possibly affected by gentrification is the secondary home market. Gentrification may breath new life into towns two or three hours away from the city. Too remote to be commuter towns, such places can be desirable weekend destinations. As more high-income families live in apartments rather than free standing houses, demand for second homes may pick up.

The only way is up? Urban sprawl had cheap housing going for it. Is the future one of ever rising land rents?

\footnotetext{
${ }^{19}$ By 18 percent, New York Times "Suburbs' Share of Poor has Grown Since 2000," May 20, 2013.
} 
East Asia may offer guidance. Japan and South Korea are both developed industrialized countries, but gentrification appears to have been largely absent [Waley, 1997]. Several factor may account for this, including close to zero population growth and low labor force participation of married women. More replicable, however, is the vertical urban landscape built around mass transportation, notably trains. High density and rail connectedness ease the pressure on land rents both by packing in and transporting more people within any given area and by allowing for multiple centers within the urban core. While the sky may not be the limit, US cities still have a lot of head room.

\section{References}

Daniel Aaronson. Neighborhood dynamics. Journal of Urban Economics, 49(1):1 - 31, 2001.

Mark Aguiar and Erik Hurst. Measuring trends in leisure: The allocation of time over five decades. Quarterly Journal of Economics, 122(3):969-1006, August 2007.

Mark Aguiar and Erik Hurst. The Increase in Leisure Inequality 19652005. The AEI Press, 2009.

David H. Autor, Lawrence F. Katz, and Melissa S. Kearney. Trends in U.S. wage inequality: Revising the revisionists. The Review of Economics and Statistics, 90(2): 300-323, May 2008.

C. F. Baum. Enhanced routines for instrumental variables/generalized method of moments estimation and testing. Stata Journal, 7(4):465-506(42), 2007. URL http://www.stata-journal.com/article.html?article=st0030_3.

Paul Beaudry, Mark Doms, and Ethan Lewis. Should the Personal Computer Be Considered a Technological Revolution? Evidence from US Metropolitan Areas. Journal of Political Economy, 118(5):988-1036, October 2010.

Christopher R. Berry and Edward L. Glaeser. The divergence of human capital levels across cities. Papers in Regional Science, 84(3):407 - 444, 2005. ISSN 10568190.

Dan Black, Gary Gates, Seth Sanders, and Lowell Taylor. Why do gay men live in San Francisco? Journal of Urban Economics, 51(1):54 - 76, 2002.

Willem R. Boterman, Lia Karsten, and Sako Musterd. Gentrifiers settling down? patterns and trends of residential location of middle-class families in Amsterdam. Housing Studies, 25(5):693 - 714, 2010.

David Card, Alexandre Mas, and Jesse Rothstein. Tipping and the dynamics of segregation. Quarterly Journal of Economics, 123(1):177-218, 2008. 
Juliet Carpenter and Loretta Lees. Gentrification in new york, london and paris: An international comparison. International Journal of Urban and Regional Research, 19 (2):286, 1995 .

Janice Compton and Robert A. Pollak. Why are power couples increasingly concentrated in large metropolitan areas? Journal of Labor Economics, 25(3):pp. 475-512, 2007.

Dora Costa and Matthew E. Kahn. Power couples: Changes in the locational choice of the college educated, 1940-1990. Quarterly Journal of Economics, 115(4):1287-1315, November 2000.

David M. Cutler, Edward L. Glaeser, and Jacob L. Vigdor. The rise and decline of the American ghetto. Journal of Political Economy, 107(3):455-506, JUN 1999.

Morris A. Davis and Jonathan Heathcote. The price and quantity of residential land in the united states. Journal of Monetary Economics, 54(8):2595 - 2620, 2007.

Rebecca Diamond. The determinants and welfare implications of US workers' diverging location choices by skill: 1980-2000. American Economic Review, Forthcoming.

Riccardo DiCecio, Kristie M. Engemann, Michael T. Owyang, and Christopher H. Wheeler. Changing trends in the labor force: A survey. Federal Reserve Bank of St. Louis Review, 90(1), January/February 2008.

John J. III Donohue and Steven D. Levitt. The impact of legalized abortion on crime. Quarterly Journal of Economics, 116(2):379-420, May 2001.

Lena Edlund and Rohini Pande. Why have women become left-wing: The political gender gap and the decline in marriage. Quarterly Journal of Economics, 117:917961, August 2002.

Alan Ehrenhalt. The Great Inversion and the Future of the American City. Vintage, paperback edition, 2013.

Giovanni Favara and Jean Imbs. Credit supply and the price of housing. American Economic Review, 105(3):958-92, 2015.

Raquel Fernndez and Joyce Wong. Unilateral divorce, the decreasing gender gap, and married women's labor force participation. American Economic Review, 104(5):34247, 2014.

Christopher Foote and Christopher Goetz. The impact of legalized abortion on crime: Comment. Quarterly Journal of Economics, 123(1), February 2008.

Edward L. Glaeser and David C. Mare. Cities and skills. Journal of Labor Economics, 19(2):316-342, 2001. 
Edward L. Glaeser, Matthew E. Kahn, and Jordan Rappaport. Why do the poor live in cities? Working Paper 7636, National Bureau of Economic Research, April 2000.

Edward L. Glaeser, Jed Kolko, and Albert Saiz. Consumer city. Journal of Economic Geography, (1):27-50, 2001.

Edward L. Glaeser, Joshua D. Gottlieb, and Kristina Tobio. Housing booms and city centers. Working Paper 17914, National Bureau of Economic Research, March 2012.

Edward L. Glaeser, Joseph Gyourko, and Albert Saiz. Housing supply and housing bubbles. Journal of Urban Economics, 64(2):198-217, SEP 2008. ISSN 0094-1190. doi: $\{10.1016 /$ j.jue.2008.07.007\}.

Jeremy Greenwood and Boyan Jovanovic. The information-technology revolution and the stock market. The American Economic Review, 89(2):pp. 116-122, 1999.

Jeremy Greenwood, Nezih Guner, Georgi Kocharkov, and Cezar Santos. Marry your like: Assortative mating and income inequality. American Economic Review, 104(5): $348-353,2014$.

Veronica Guerrieri, Daniel Hartley, and Erik Hurst. Within-city variation in urban decline: The case of Detroit. American Economic Review: Papers and Proceedings, 102(3):120126, 2012.

Veronica Guerrieri, Daniel Hartley, and Erik Hurst. Endogenous gentrifcation and housing price dynamics. Journal of Public Economics, 100:45-60, 2013.

Joseph Gyourko, Christopher Mayer, and Todd Sinai. Superstar cities. American Economic Journal: Economic Policy, 5(4):167-99, 2013.

Bradley T. Heim. The incredible shrinking elasticities: Married female labor supply, 1978-2002. The Journal of Human Resources, 42(4):pp. 881-918, 2007.

Bart Hobijn and Boyan Jovanovic. The information-technology revolution and the stock market: Evidence. The American Economic Review, 91(5):pp. 1203-1220, 2001.

Kenneth T. Jackson. Crabgrass Frontier. Oxford University Press, 1985.

Jane Jacobs. The Death and Life of Great American Cities. Random House, New York, 1961.

William R. Johnson. House prices and female labor force participation. University of Virginia, January 2012.

Chinhui Juhn and Kevin M. Murphy. Wage inequality and family labor supply. Journal of Labor Economics, 15(1):72-97, January 1997.

Chinhui Juhn, Kevin M. Murphy, and Brooks Pierce. Wage inequality and the rise in returns to skill. Journal of Political Economy, 101(3):410-442, June 1993. 
Matthew E. Kahn. Gentrification trends in new transit-oriented communities: Evidence from 14 cities that expanded and built rail transit systems. Real Estate Economics, 35(2):155-182, Sum 2007.

Lawrence F. Katz and Kevin M. Murphy. Changes in the relative wages, 1963-87: supply and demand factors. Quarterly Journal of Economics, 107(1):35-78, February 1992.

Elizabeth Kneebone and Alan Berube. Confronting Suburban Poverty in America. James A. Johnson Metro. Brookings Institution Press, 2013.

Wojciech Kopczuk, Emmanuel Saez, and Jae Song. Uncovering the American dream: Inequality and mobility in social security earnings data since 1937. NBER Working Paper, (13345), 2008.

Peter J. Kuhn and Fernando A. Lozano. The expanding workweek? understanding trends in long work hours among U.S. men, 1979-2004. Discussion Paper 1924, IZA, 2006.

Janice F. Madden and Michelle J. White. Spatial implications of increases in the female labor force: A theoretical and empirical synthesis. Land Economics, 56(4):432-446, Nov. 1980.

Janice Fanning Madden. Consequences of the growth of the two-earner eamily urban land use and the growth in two-earner households. American Economic Review, 70 (2):191-197, 1980 .

Scott C. McDonald. Does gentrification affect crime rates. Crime \& Just., 8:163, 1986.

Ellen McGrattan and Richard Rogerson. Changes in the distribution of family hours worked since 1950. Research Department Staff Report 397, Federal Reserve Bank of Minneapolis, 2008.

Brian McKenzie and Melanie Rapino. Commuting in the united states, 2009. American Community Survey Reports ACS-15, Census Bureau, Washington, DC, 2011.

Peter Mieszkowski and Edwin S. Mills. The causes of metropolitan suburbanization. Journal of Economic Perspectives, 7(3):135-147, Sum 1993.

Enrico Moretti. Real wage inequality. American Economic Journal-Applied Economics, 5(1):65-103, Jan 2013.

National Association of Realtors. Home buyer and seller generational trends. Technical report, 2014. http://www.realtor.org/sites/default/files/reports/2014/2014-homebuyer-and-seller-generational-trends-report-full.pdf.

Francois Ortalo-Magne and Andrea Prat. On the political economy of urban growth: Homeownership versus affordability. American Economic Journal: Microeconomics, 6(1):154-81, 2014. 
Jordan Rappaport. Monocentric city redux. Research Working Paper 14-09, The Federal Reserve Bank of Kansas City, 2014. https://www.kansascityfed.org/publicat/reswkpap/pdf/rwp14-09.pdf.

Jessica Wolpaw Reyes. Environmental policy as social policy? The impact of childhood lead exposure on crime. B E Journal of Economic Analysis $\&$ Policy, 7(1), 2007.

Gilles Saint-Paul. Bobos in paradise: Urban politics and the new economy. Discussion Paper 10879, Centre for Economic Policy Research, 2015.

Thomas C. Schelling. Models of segregation. American Economic Review, 59(2):488493, 1969. ISSN 0002-8282.

Christine R. Schwartz. Earnings inequality and the changing association between spouses earnings. American Journal of Sociology, 115(5):pp. 1524-1557, 2010.

James H. Stock and Motohiro Yogo. Testing for weak instruments in linear iv regression. In Donald W. K. Andrews and James H. Stock, editors, Identification and Inference for Econometric Models: Essays in Honor of Thomas Rothenberg. Cambridge University Press, 2005. http://dx.doi.org/10.1017/CBO9780511614491.006.

Stijn Van Nieuwerburgh and Pierre-Olivier Weill. Why has house price dispersion gone up? The Review of Economic Studies, 77(4):1567-1606, 2010.

Paul Waley. Tokyo - patterns of familiarity and partitions of difference. American Behavioral Scientist, 41(3):396-429, 1997.

Michelle J. White. A model of residential location choice and commuting by men and women workers. Journal of Regional Science, 17(1):41-51, 1977. 


\section{Graphs}

Figure 1: Home Prices by location

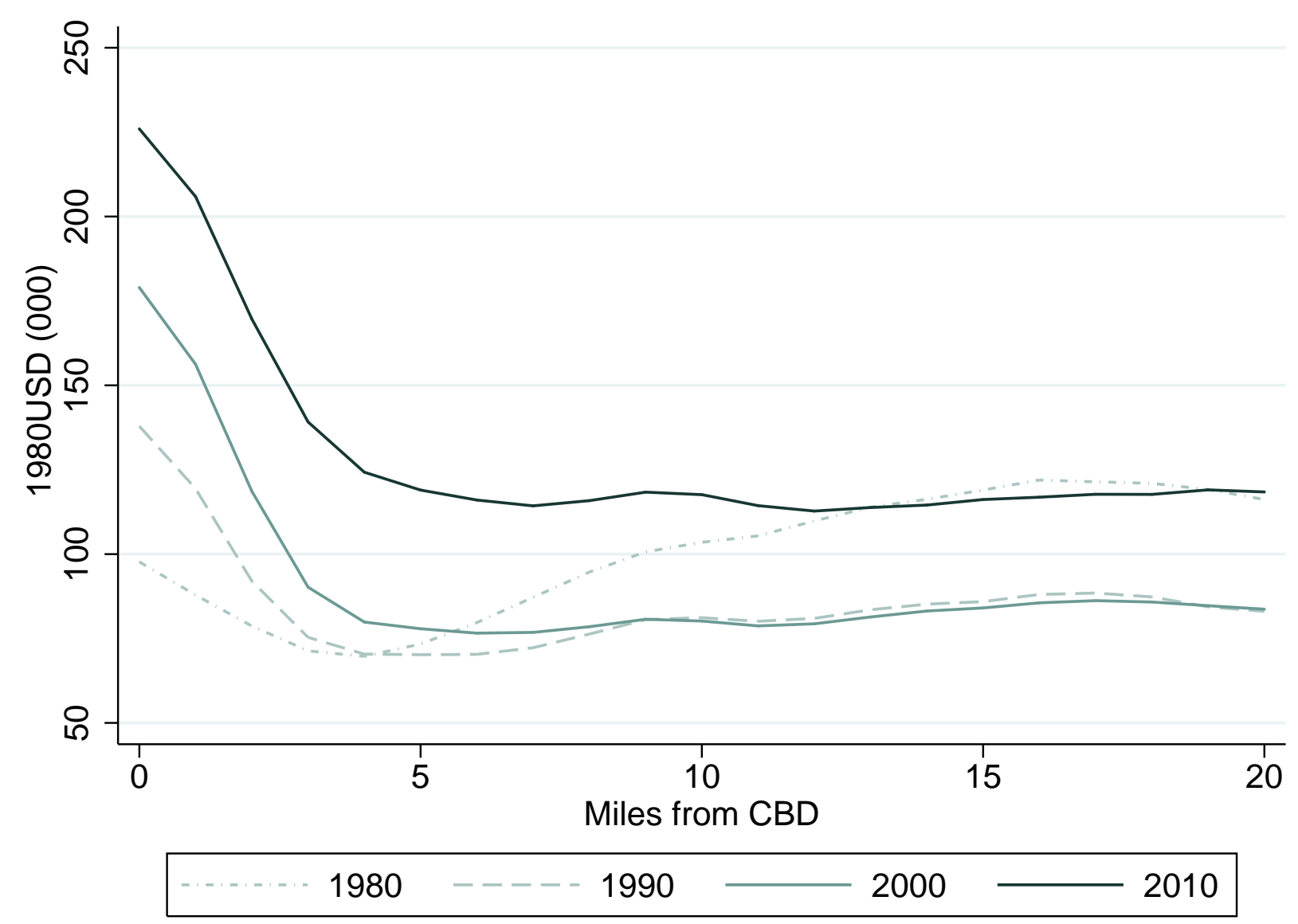

Notes: Owner-occupied, 2-3 bedroom, one-family homes. 20 miles includes 20-35 miles. Source: Decennial censuses and the American Community Survey, restricted use data. 
Figure 2: \% Working full time, 40h/week, by sex and education

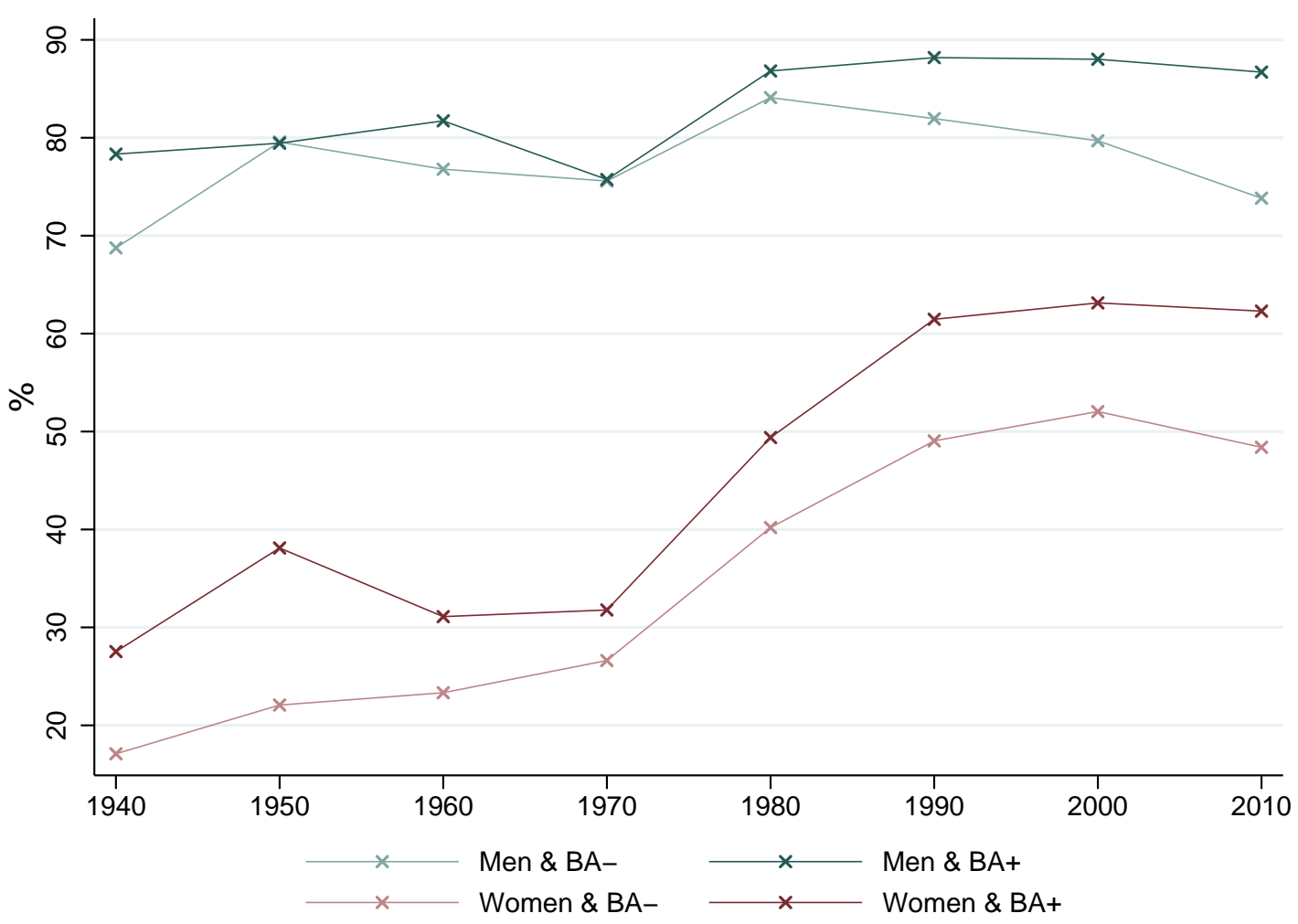

Note: Ages 25-55.

Source: Decennial censuses, integrated public use micro data series (IPUMS). 
Figure 3: \% Working full time, 50h/week, by sex and education

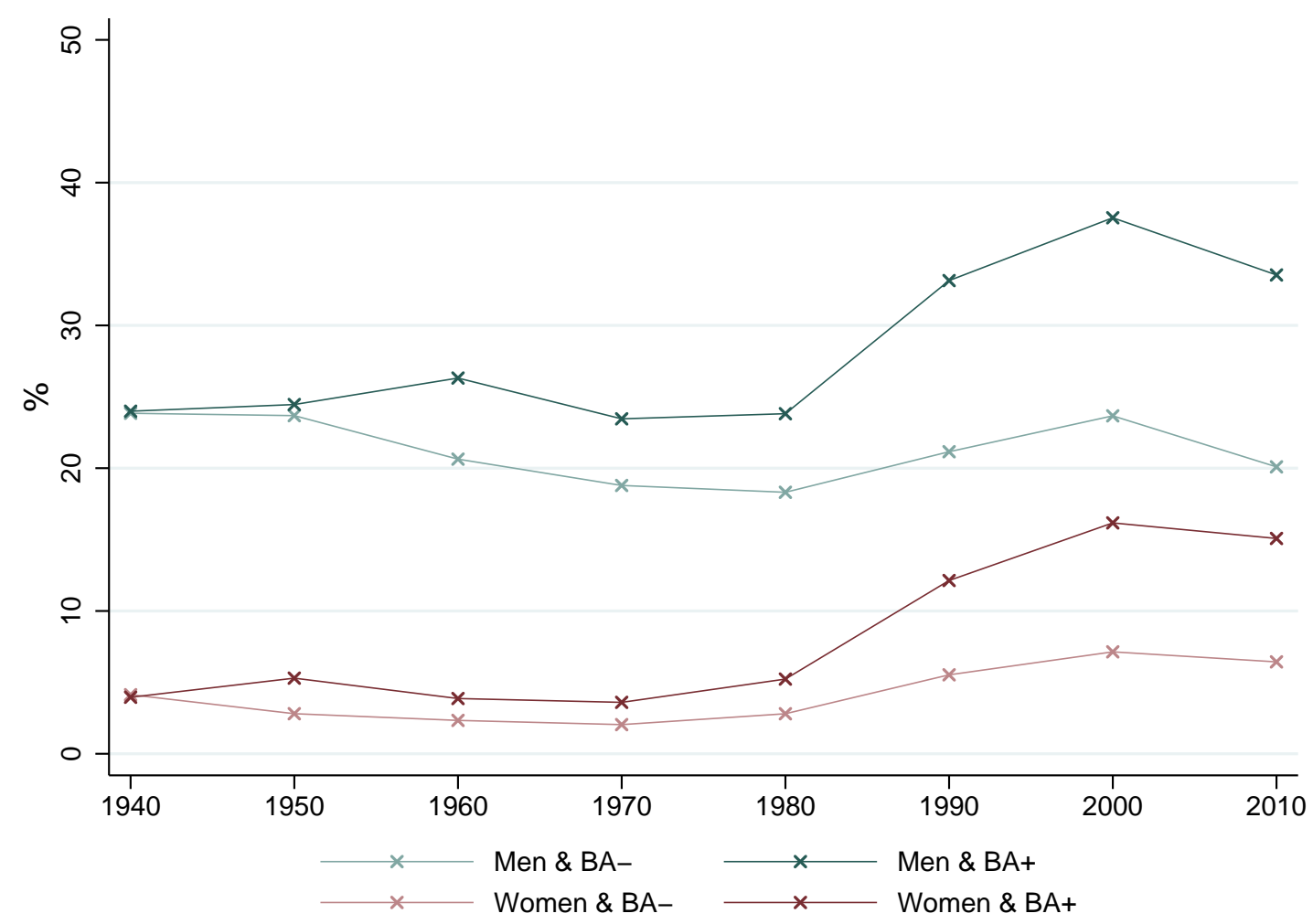

Note: Ages 25-55.

Source: Decennial censuses, integrated public use micro data series (IPUMS). 
Figure 4: \% full time and skilled among men 25-55
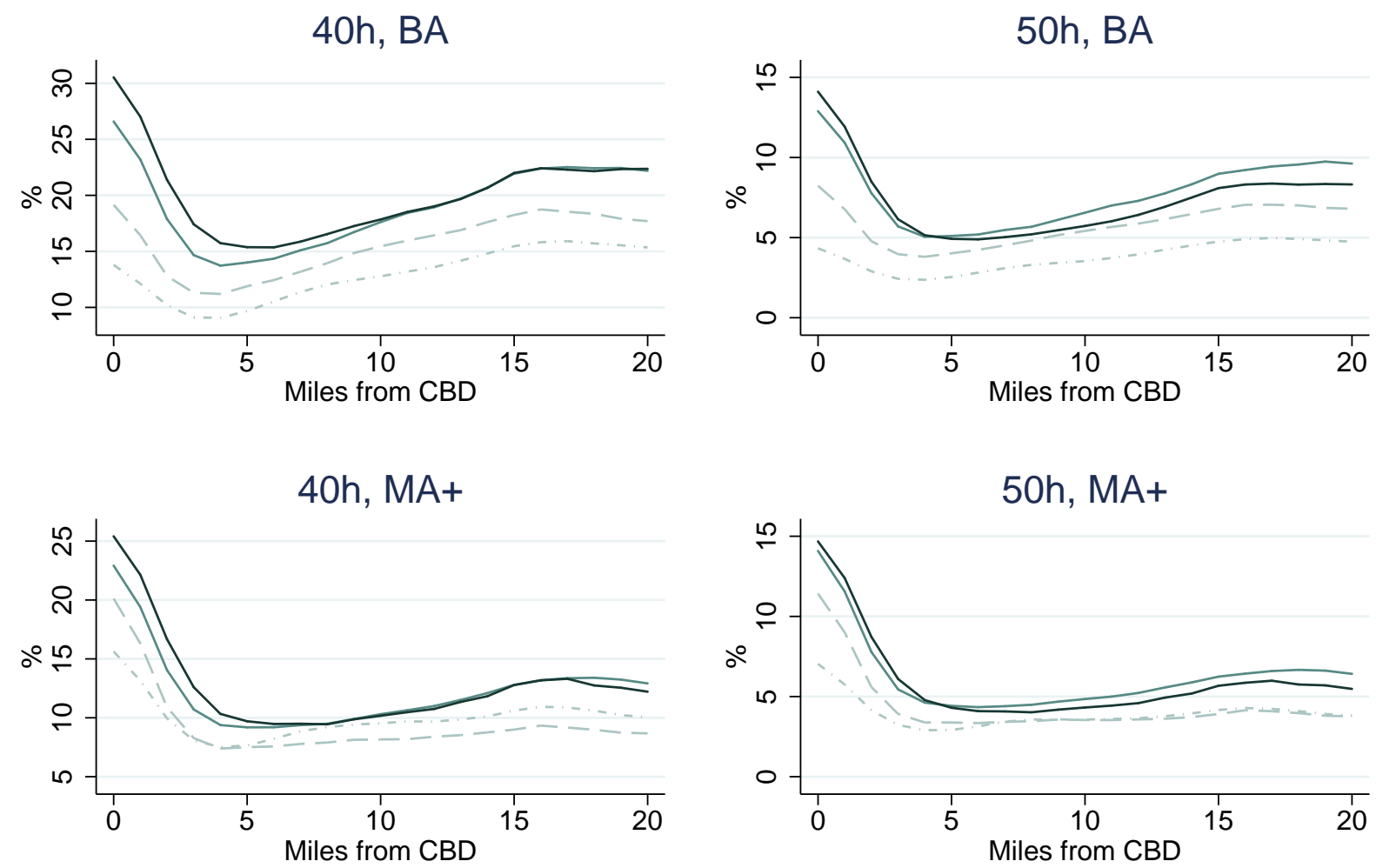

$$
2010
$$

Universe: Men 25-55 residing $x=0,1, \ldots 18,19,20-35$ miles from the CBD. Source: Decennial censuses and the American Community Survey, restricted use data. 
Figure 5: \% full time and skilled among women 25-55
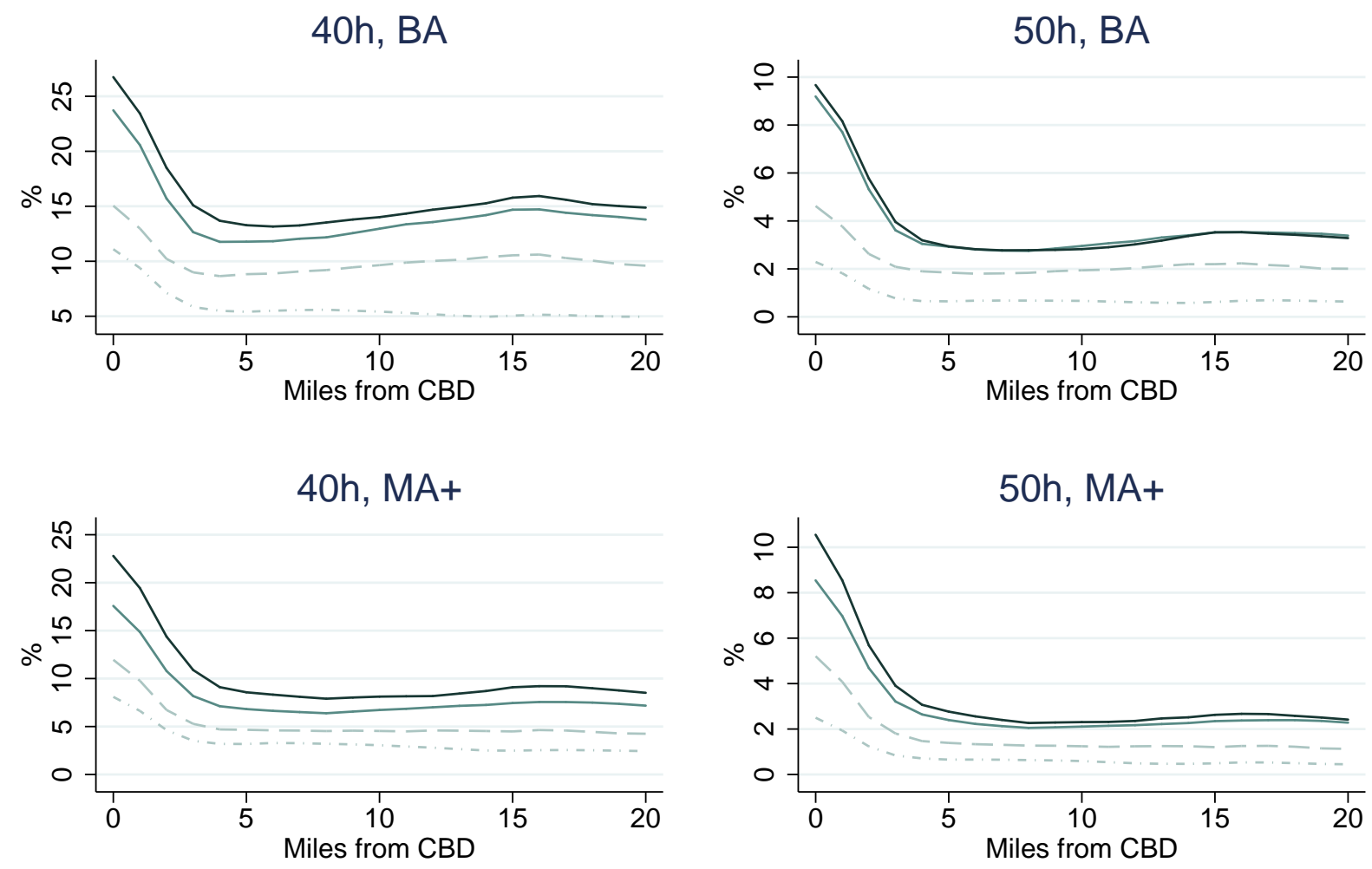

\section{0}

Universe: Women 25-55 residing $x=0,1, \ldots 18,19,20-35$ miles from the CBD. Source: Decennial censuses and the American Community Survey, restricted use data. 
Figure 6: Jobs by skill

$\mathrm{BA}-$

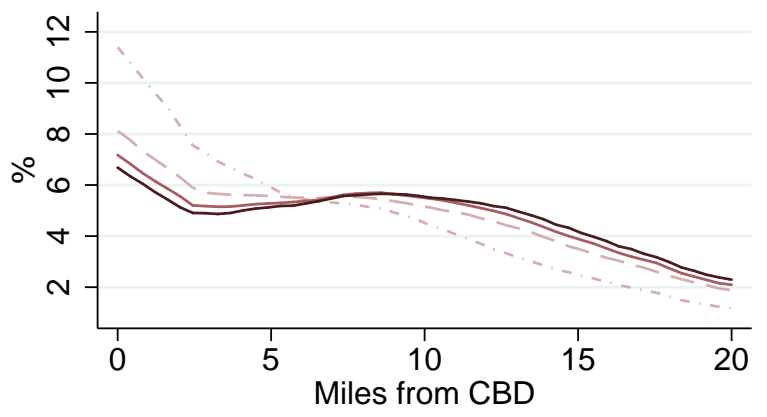

$\mathrm{BA}+$

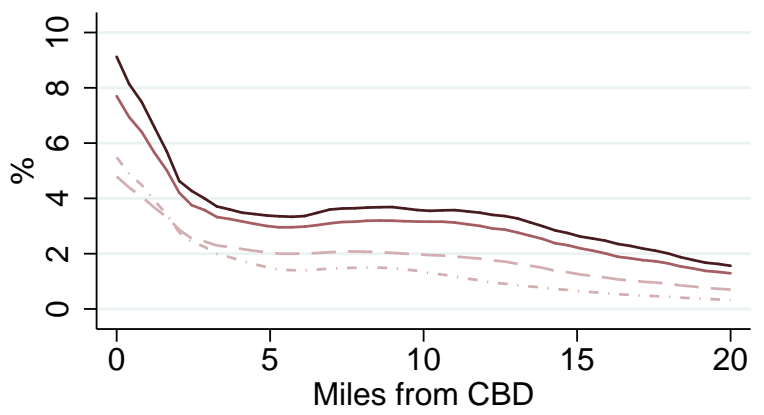

BA

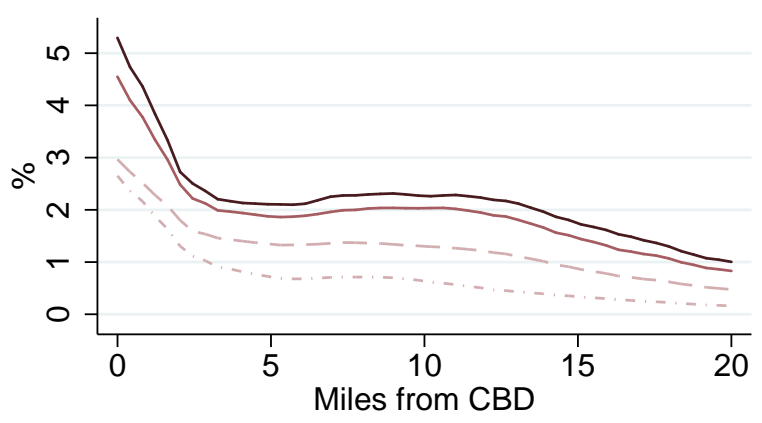

$\mathrm{MA}+$

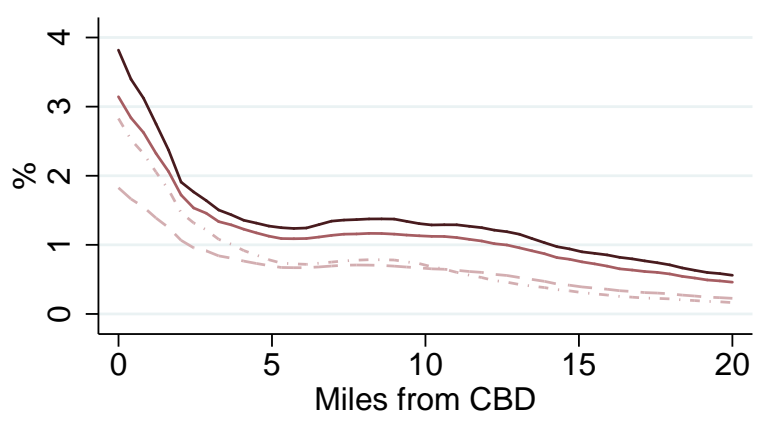

2000

Universe: filled jobs within 35 miles of the CBD.

Source: Decennial censuses and the American Community Survey, restricted use data. 
Figure 7: Commuting time by education and residence location, men
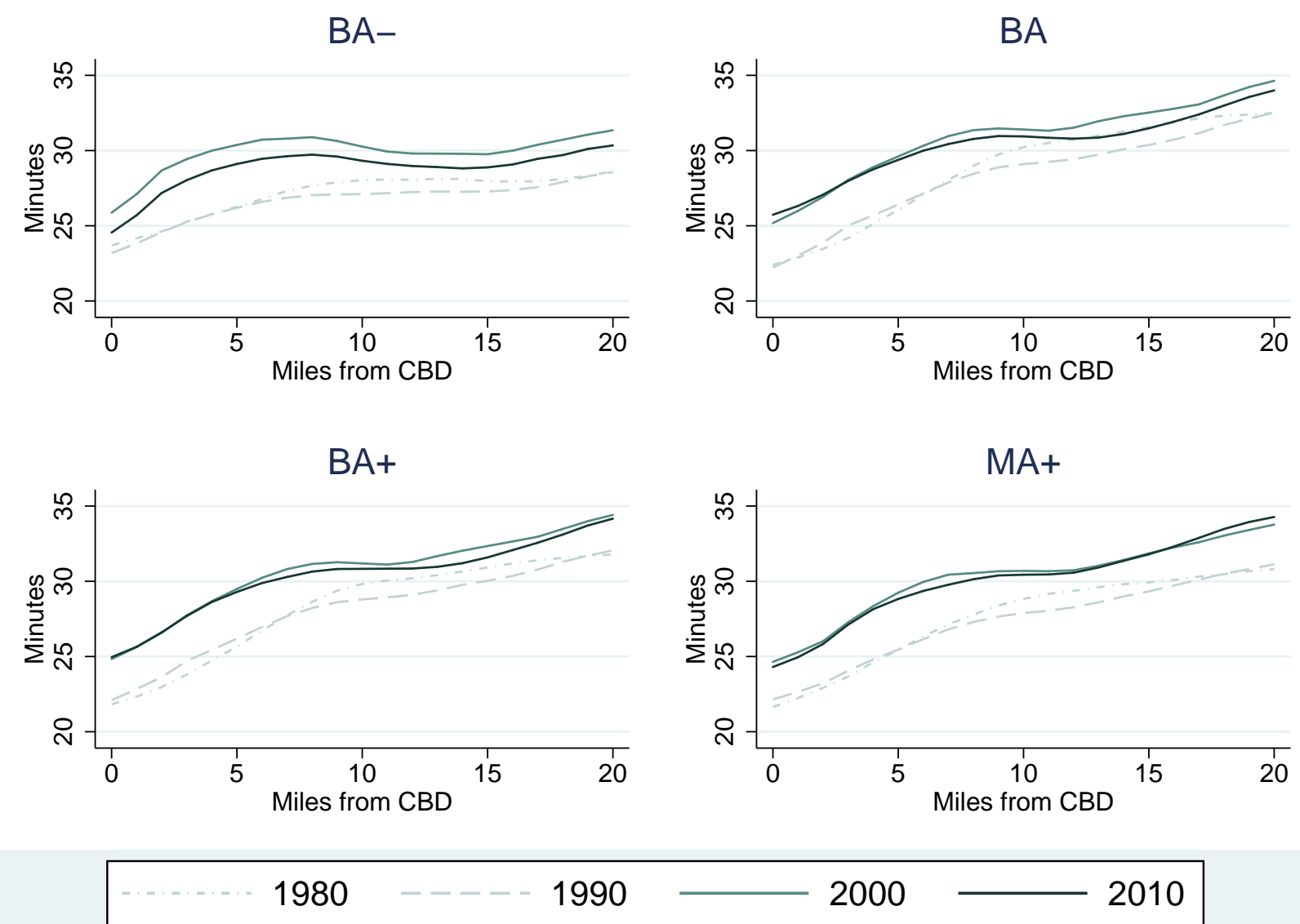

One way, door-to-door.

Universe: Men 25-55 who work away from home.

Source: Decennial censuses and the American Community Survey, restricted use data. 
Figure 8: Commuting time by education and residence location, women
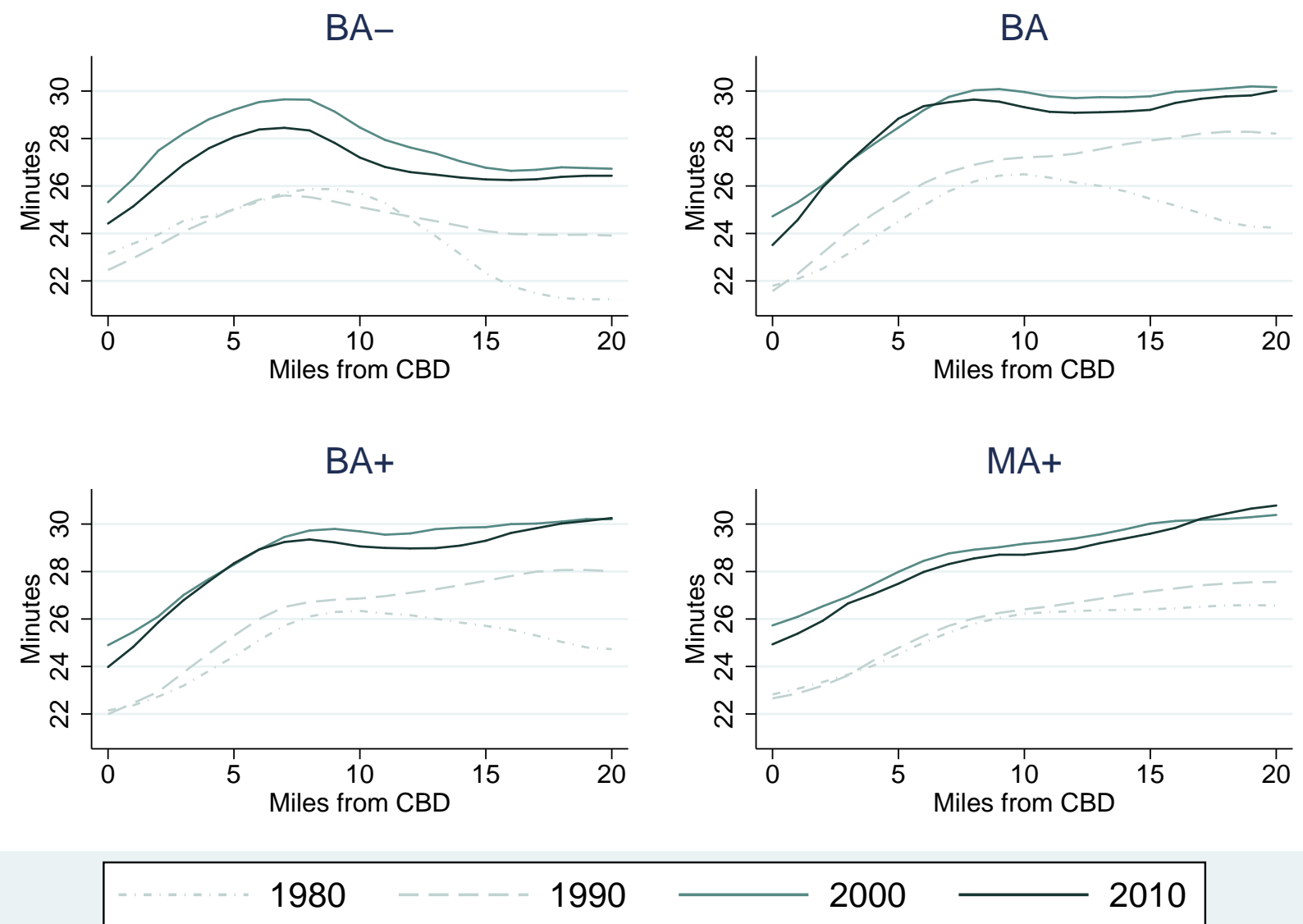

One way, door-to-door.

Universe: Women 25-55 who work away from home.

Source: Decennial censuses and the American Community Survey, restricted use data. 
Figure 9: Commuting time, by sex, education, and residence location
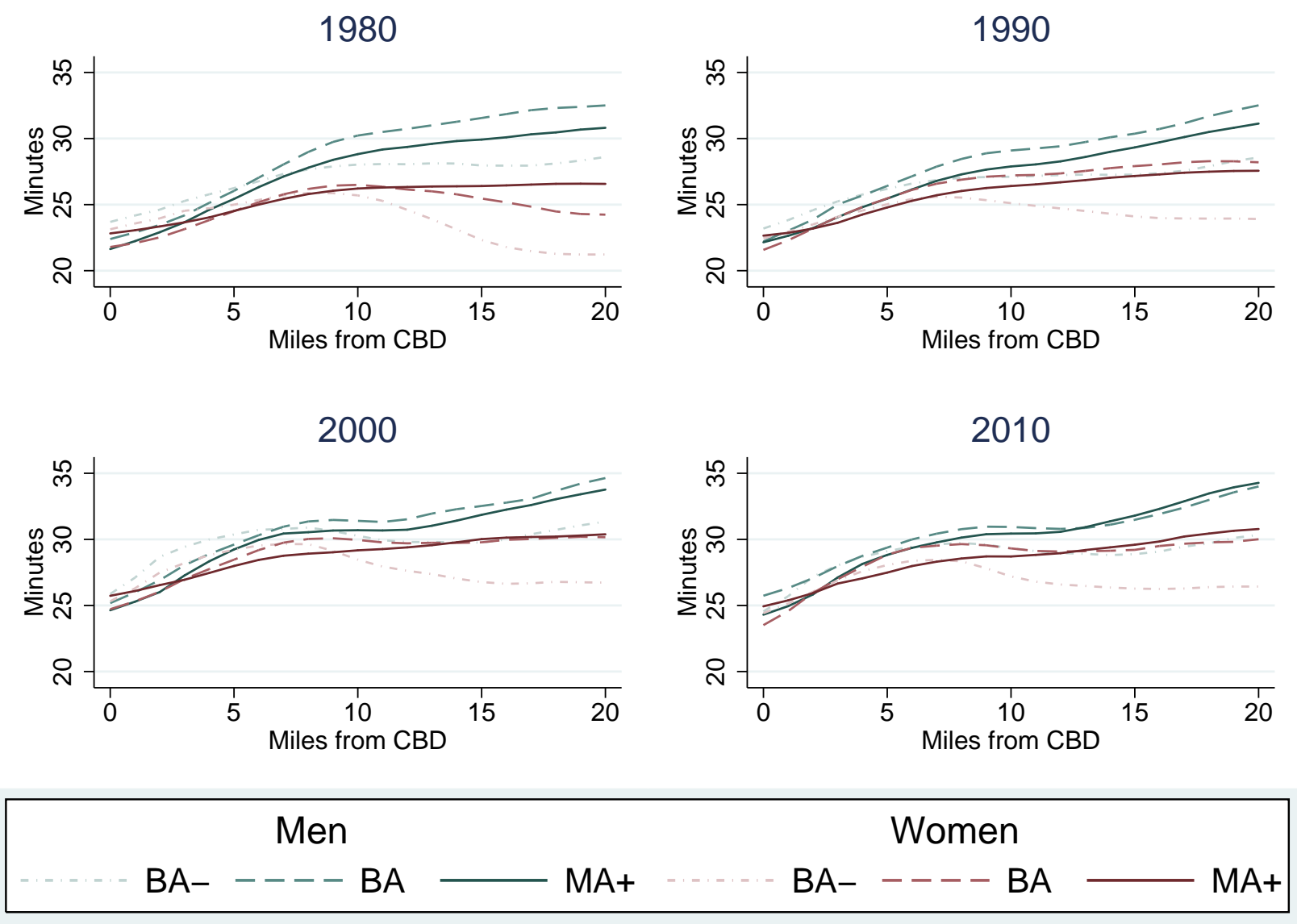

Universe: Men and women 25-55 who work away from home. Source: Decennial censuses and the American Community Survey, restricted use data. 
Figure 10: Age distribution by residence location

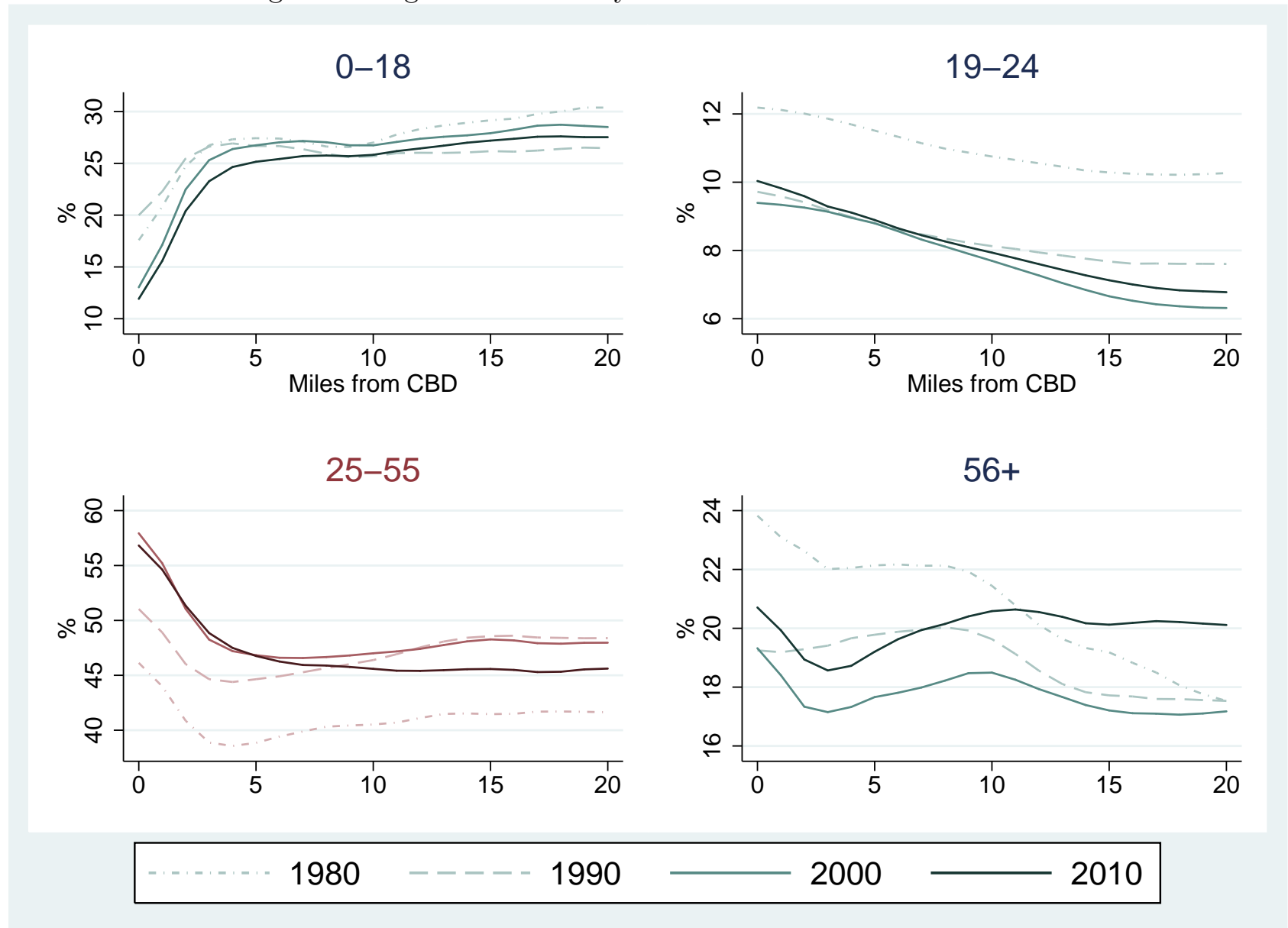

Universe: Residents residing $x=0,1, \ldots 18,19,20-35$ miles from the CBD.

Source: Decennial censuses and the American Community Survey, restricted use data. 
Figure 11: Predicted v. Actual Price increase, ‘000 1980\$

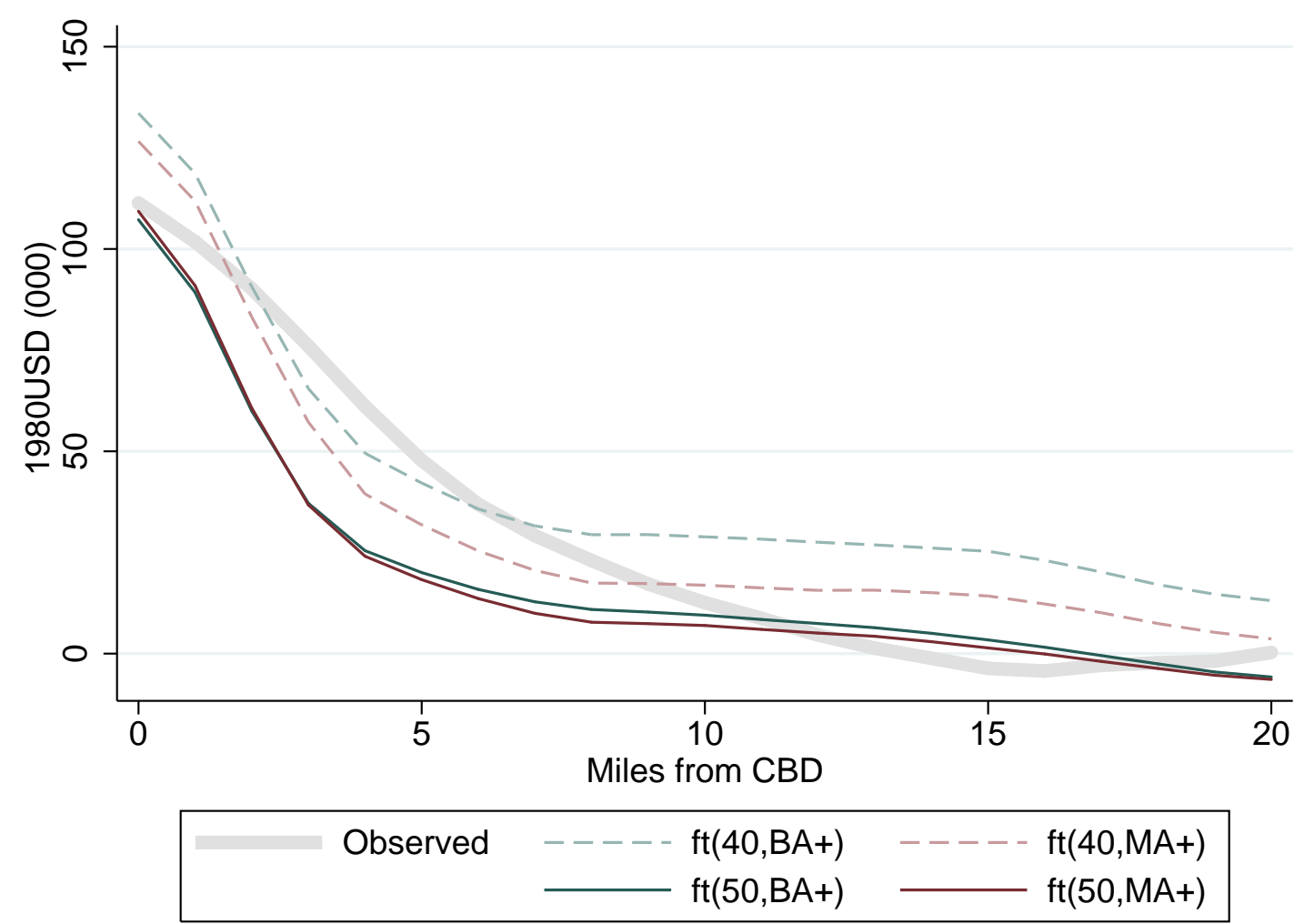


Figure 12: Predicted v. Actual Price increase, ‘000 1980\$

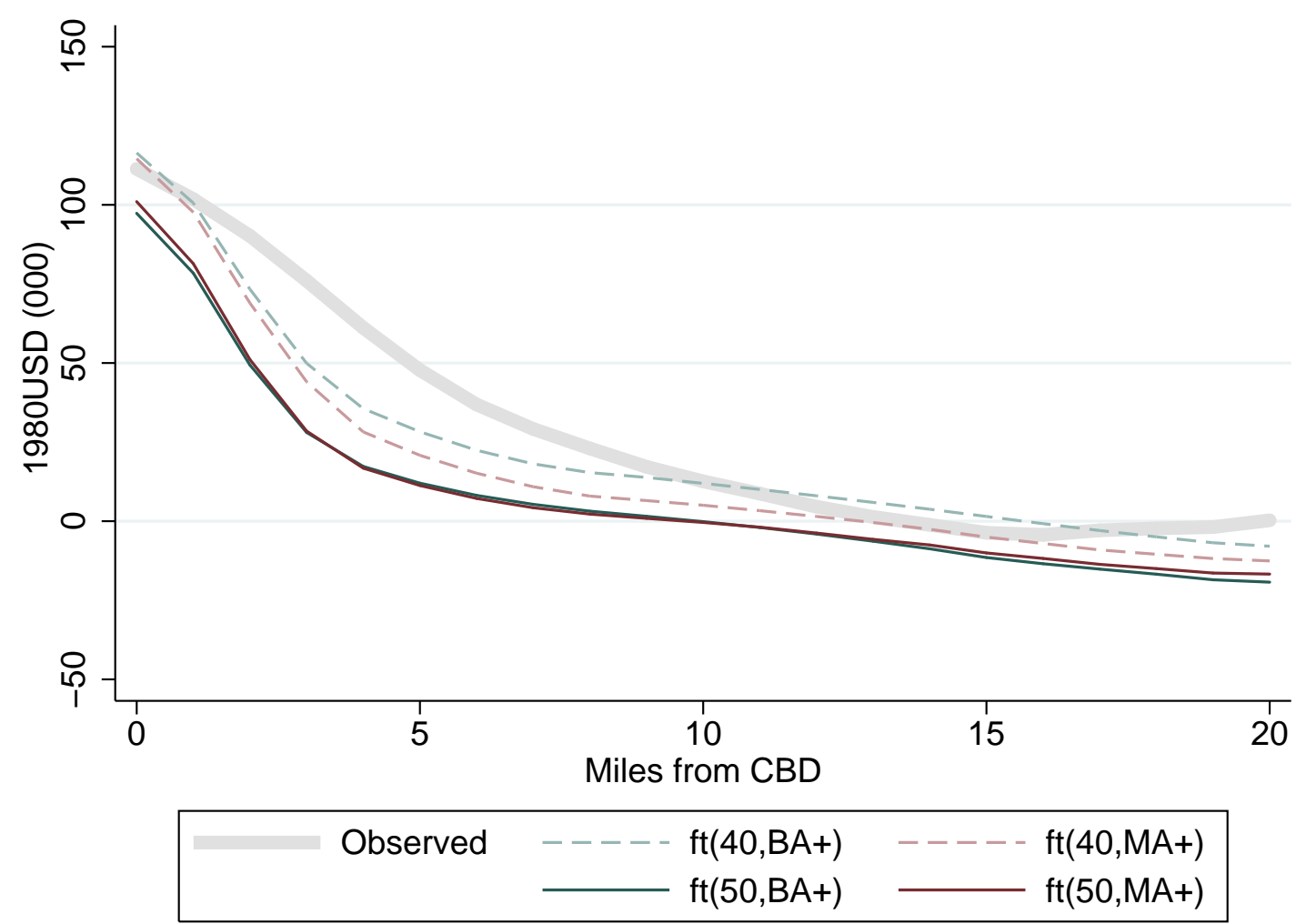




\section{Tables}

Unless otherwise specified, the analysis is based on the decennial censuses and the American Community Survey, restricted use data. Throughout, sample sizes have been rounded to nearest 1000 for disclosure reasons. The repeated cross section has 65

thousand tract-years (53 thousand excluding New York); and the panel data set has 48 thousand tract-years. 
Table 1: Summary Statistics

\begin{tabular}{|c|c|c|c|c|c|c|}
\hline \multirow[b]{3}{*}{ Variable } & \multirow[b]{3}{*}{ Year } & (1) & $(2)$ & $(3)$ & $(4)$ & $(5)$ \\
\hline & & \multicolumn{5}{|c|}{ Distance to the CBD (miles) } \\
\hline & & $d 1=[0,3]$ & $d 2=(3,10]$ & $d 3=(10,20]$ & $d 4=(20,35)$ & {$[0,35)$} \\
\hline \multirow{3}{*}{$\begin{array}{l}\text { House price } \\
(' 0001980 \$)\end{array}$} & 1980 & 66.64 & 79.16 & 108.23 & 114.06 & 92.5 \\
\hline & 2010 & 154.77 & 115.07 & 119.22 & 120.5 & 120.54 \\
\hline & $\Delta$ & 88.13 & 35.91 & 10.99 & 6.44 & 28.04 \\
\hline \multirow{3}{*}{$\mathrm{FT}(40, \mathrm{BA}+)$} & 1980 & 13.78 & 12.92 & 15.19 & 15.05 & 14.05 \\
\hline & 2010 & 35.13 & 23.15 & 27.22 & 28.29 & 26.62 \\
\hline & $\Delta$ & 21.35 & 10.23 & 12.03 & 13.24 & 12.57 \\
\hline \multirow[t]{3}{*}{$\mathrm{FT}(40, \mathrm{MA}+)$} & 1980 & 6.37 & 5.42 & 6.12 & 5.64 & 5.77 \\
\hline & 2010 & 15.5 & 8.92 & 10.1 & 10.35 & 10.13 \\
\hline & $\Delta$ & 9.13 & 3.5 & 3.98 & 4.71 & 4.36 \\
\hline \multirow{3}{*}{$\mathrm{FT}(50, \mathrm{BA}+)$} & 1980 & 4.03 & 3.43 & 4.3 & 4.44 & 3.92 \\
\hline & 2010 & 14.32 & 7.25 & 8.81 & 9.69 & 8.86 \\
\hline & $\Delta$ & 10.29 & 3.82 & 4.51 & 5.25 & 4.94 \\
\hline \multirow[t]{3}{*}{$\mathrm{FT}(50, \mathrm{MA}+)$} & 1980 & 2.29 & 1.82 & 2.06 & 1.93 & 1.96 \\
\hline & 2010 & 7.28 & 3.4 & 3.8 & 4.02 & 3.95 \\
\hline & $\Delta$ & 4.99 & 1.58 & 1.74 & 2.09 & 1.99 \\
\hline \multirow{3}{*}{$\begin{array}{l}\text { Income } \\
\text { ('000 1980\$) }\end{array}$} & 1980 & 10.53 & 12.06 & 14.25 & 14.3 & 12.94 \\
\hline & 2010 & 17.98 & 13.99 & 17.22 & 18.77 & 16.53 \\
\hline & $\Delta$ & 7.45 & 1.93 & 2.97 & 4.47 & 3.59 \\
\hline \multirow[t]{3}{*}{ White } & 1980 & 48.99 & 62.43 & 75.61 & 85.73 & 68.87 \\
\hline & 2010 & 44.97 & 38.81 & 53.91 & 66.37 & 51.06 \\
\hline & $\Delta$ & -4.02 & -23.62 & -21.7 & -19.36 & -17.81 \\
\hline \multirow[t]{3}{*}{ Black } & 1980 & 32.89 & 23.61 & 13.41 & 6.78 & 18.7 \\
\hline & 2010 & 25 & 27.22 & 15.43 & 7.49 & 18.25 \\
\hline & $\Delta$ & -7.89 & 3.61 & 2.02 & 0.71 & -0.45 \\
\hline \multirow[t]{3}{*}{ Married } & 1980 & 46.29 & 62.67 & 72.22 & 77.35 & 66.32 \\
\hline & 2010 & 36.13 & 48.25 & 60.72 & 66.59 & 56.14 \\
\hline & $\Delta$ & -10.16 & -14.42 & -11.5 & -10.76 & -10.18 \\
\hline
\end{tabular}


Table 1: Summary Statistics, continued

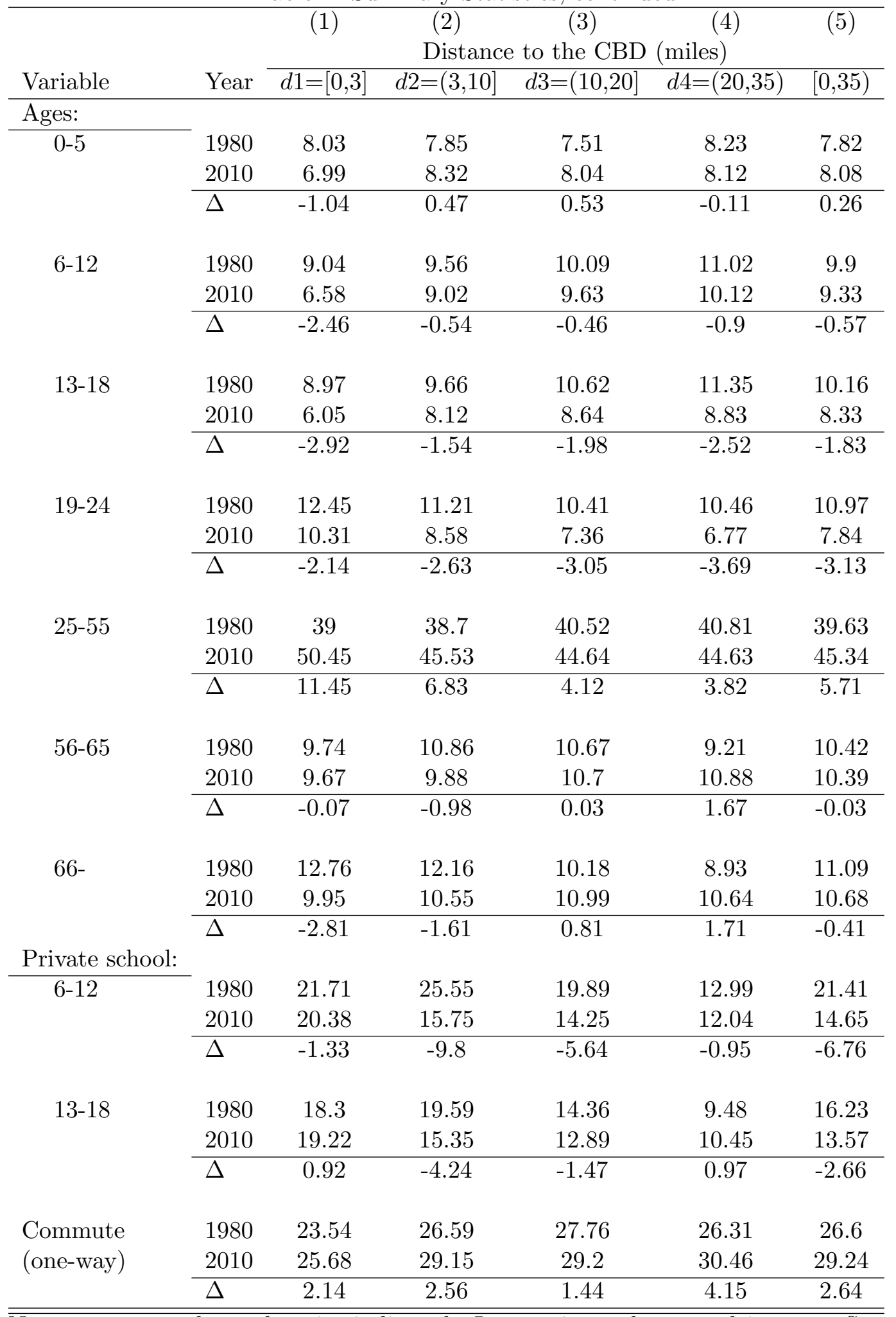

Note: percent unless otherwise indicated 43 Income is total personal income. Source: Decennial censuses and the American Community Survey, restricted use data. 
Table 2: The Effects of Demand Shock on Housing Values

\begin{tabular}{|c|c|c|c|c|c|c|c|c|}
\hline & \multicolumn{7}{|c|}{ House price ('000) $1980 \$$} & (8) \\
\hline$Z$ & $\begin{array}{c}425.7 \\
{[264.1]}\end{array}$ & & & & $\begin{array}{c}442.3 \\
{[298.6]}\end{array}$ & & & \\
\hline$Z \times$ & & & & & & & & \\
\hline$d 1$ & $\begin{array}{c}588.9 * * \\
{[168.6]}\end{array}$ & $\begin{array}{c}580.7^{* *} \\
{[169.1]}\end{array}$ & & & $\begin{array}{c}602.9^{* * *} \\
{[121.2]}\end{array}$ & $\begin{array}{c}633.1^{* * *} \\
{[123.1]}\end{array}$ & & \\
\hline$d 2$ & $\begin{array}{c}234.5^{* * *} \\
{[52.21]}\end{array}$ & $\begin{array}{c}249.7^{* * *} \\
{[49.95]}\end{array}$ & & & $\begin{array}{c}222.0^{* *} \\
{[61.10]}\end{array}$ & $\begin{array}{c}285.2^{* * * *} \\
{[54.47]}\end{array}$ & & \\
\hline$d 3$ & $\begin{array}{c}88.25^{* * *} \\
{[18.25]}\end{array}$ & $\begin{array}{c}98.22^{* * *} \\
{[18.49]}\end{array}$ & & & $\begin{array}{c}124.5^{* *} \\
{[36.41]}\end{array}$ & $\begin{array}{c}153.8^{* * * *} \\
{[41.01]}\end{array}$ & & \\
\hline dist & & & $\begin{array}{c}-50.30^{* *} \\
{[13.92]}\end{array}$ & $\begin{array}{c}-95.95^{*} \\
{[39.10]}\end{array}$ & & & $\begin{array}{c}-47.81^{* * *} \\
{[7.842]}\end{array}$ & $\begin{array}{c}-87.37^{*} \\
{[32.77]}\end{array}$ \\
\hline$d i s t^{2}$ & & & $\begin{array}{c}1.053^{* *} \\
{[0.307]}\end{array}$ & $\begin{array}{l}4.479+ \\
{[2.268]}\end{array}$ & & & $\begin{array}{c}0.928 * * * \\
{[0.156]}\end{array}$ & $\begin{array}{l}3.735+ \\
{[1.997]}\end{array}$ \\
\hline$d i s t^{3}$ & & & & $\begin{array}{r}-0.0693+ \\
{[0.0404]}\end{array}$ & & & & $\begin{array}{l}-0.0537 \\
{[0.0364]}\end{array}$ \\
\hline$R^{2}$ & 0.333 & 0.362 & 0.353 & 0.359 & 0.372 & 0.400 & 0.401 & 0.402 \\
\hline Fixed effects: & & & & & & & & \\
\hline $\begin{array}{l}\text { City } \\
\text { Year }\end{array}$ & $\sqrt{ }$ & & & & $\mathscr{J}$ & & & \\
\hline $\begin{array}{l}\text { City-year } \\
\text { City-distance }\end{array}$ & & $\sqrt{ }$ & & $\sqrt{ }$ & $\sqrt{ }$ & $\begin{array}{l}\checkmark \\
\checkmark\end{array}$ & $\begin{array}{l}\checkmark \\
\checkmark\end{array}$ & $\begin{array}{l}\sqrt{ } \\
\sqrt{ }\end{array}$ \\
\hline$N(' 000)$ & 65 & 65 & 65 & 65 & 65 & 65 & 65 & 65 \\
\hline
\end{tabular}

$Z$ is the Bartik demand shifter, calculated per Equation 1, also see Table A2. Regressions $1,2,5$, and 6 include the vector $(d 1, d 2, d 3)$; regressions 3 , and 7 include the vector $\left(d i s t, d i s t^{2}\right)$; regressions 4 , and 8 include the vector $\left(d i s t, d i s t^{2}, d i s t^{3}\right)$. Significance levels: *** $-0.001 ; * *-0.01 ; *-0.05 ;+-0.1$.

Source: Decennial censuses and the American Community Survey, restricted use data. 
Table 3: The Effects of Demand Shock on Tract Characteristics

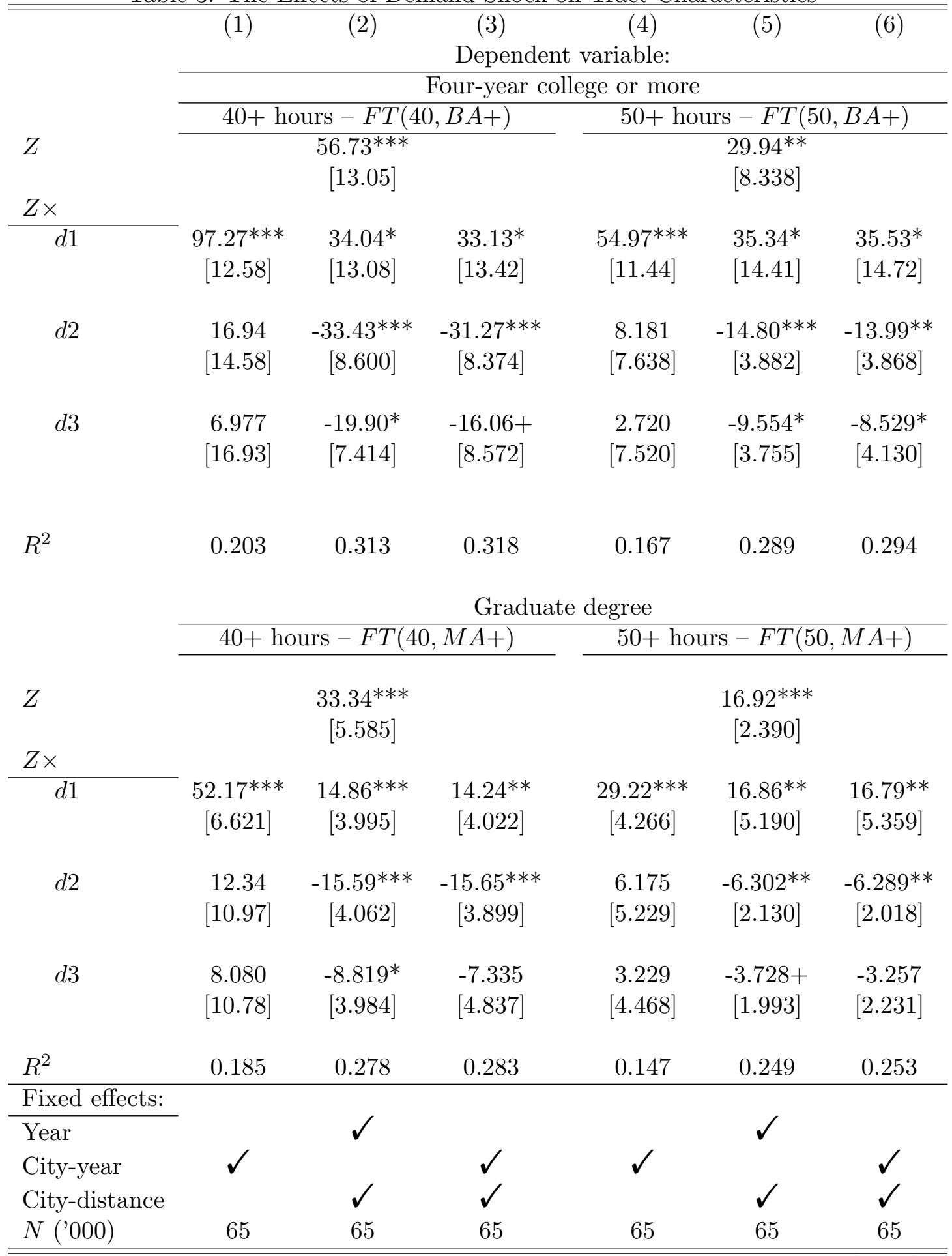

$\bar{Z}$ is the Bartik demand shifter, calculated per Equation 1, also see Table A2. All regressions include the vector $(d 1, d 2, d 3)$. Significance levels: $* * *-0.001 ; * *-0.01{ }^{*}$ $-0.05 ;+-0.1$. 
Table 4: The Effects of Demand Shock on Tract Characteristics

\begin{tabular}{|c|c|c|c|c|c|c|}
\hline & (1) & $(2)$ & $(3)$ & $(4)$ & $(5)$ & (6) \\
\hline & & & Depend & variable: & & \\
\hline & & Black, \% & & non- & Gispanic Wh & ite, $\%$ \\
\hline$Z$ & & -14.23 & & & $-98.88^{* * *}$ & \\
\hline & & {$[47.26]$} & & & [22.88] & \\
\hline$Z \times$ & & & & & & \\
\hline$d 1$ & $\begin{array}{c}-109.5^{*} \\
{[41.32]}\end{array}$ & $\begin{array}{c}-44.86^{* * *} \\
{[10.22]}\end{array}$ & $\begin{array}{c}-51.15^{* * *} \\
{[13.73]}\end{array}$ & $\begin{array}{c}166.2^{* * *} \\
{[34.36]}\end{array}$ & $\begin{array}{c}95.98^{* * *} \\
{[21.11]}\end{array}$ & $\begin{array}{c}94.61^{* * *} \\
{[21.87]}\end{array}$ \\
\hline$d 2$ & -39.96 & 14.62 & 10.62 & 29.94 & -32.64 & -30.46 \\
\hline & {$[34.53]$} & {$[17.21]$} & [16.59] & {$[22.17]$} & {$[23.65]$} & {$[27.08]$} \\
\hline$d 3$ & 12.43 & $28.19^{*}$ & $30.75^{* *}$ & -25.31 & $-41.20^{* *}$ & $-36.33^{*}$ \\
\hline & [7.923] & {$[10.46]$} & {$[9.638]$} & [16.85] & [14.66] & {$[14.43]$} \\
\hline$R^{2}$ & 0.167 & 0.273 & 0.279 & 0.348 & 0.438 & 0.443 \\
\hline & & Married, $\%$ & & Income, & personal ('oc & 00) $1980 \$$ \\
\hline$Z$ & & $\begin{array}{c}85.94^{* *} \\
{[26.00]}\end{array}$ & & & $\begin{array}{c}56.39^{* * *} \\
{[11.01]}\end{array}$ & \\
\hline$Z \times$ & & & & & & \\
\hline$d 1$ & $\begin{array}{c}16.47 \\
{[21.43]}\end{array}$ & $\begin{array}{l}16.35+ \\
{[8.860]}\end{array}$ & $\begin{array}{l}18.36^{*} \\
{[8.380]}\end{array}$ & $\begin{array}{c}34.72^{* * *} \\
{[9.205]}\end{array}$ & $\begin{array}{c}10.85 \\
{[8.083]}\end{array}$ & $\begin{array}{c}9.107 \\
{[8.628]}\end{array}$ \\
\hline$d 2$ & $\begin{array}{c}1.334 \\
{[9.552]}\end{array}$ & $\begin{array}{c}-27.29 * * \\
{[8.193]}\end{array}$ & $\begin{array}{c}-26.71^{* *} \\
{[8.146]}\end{array}$ & $\begin{array}{l}-0.534 \\
{[10.95]}\end{array}$ & $\begin{array}{c}-24.97^{* * *} \\
{[6.044]}\end{array}$ & $\begin{array}{c}-24.70^{* * *} \\
{[5.899]}\end{array}$ \\
\hline$d 3$ & $\begin{array}{l}-5.436 \\
{[7.039]}\end{array}$ & $\begin{array}{c}-17.31^{* *} \\
{[5.367]}\end{array}$ & $\begin{array}{c}-19.29 * * \\
{[5.899]}\end{array}$ & $\begin{array}{l}-1.104 \\
{[8.898]}\end{array}$ & $\begin{array}{c}-13.28^{*} \\
{[4.792]}\end{array}$ & $\begin{array}{c}-11.98^{*} \\
{[5.183]}\end{array}$ \\
\hline$R^{2}$ & 0.374 & 0.470 & 0.475 & 0.163 & 0.285 & 0.293 \\
\hline Fixed effects: & & & & & & \\
\hline Year & & $\sqrt{ }$ & & & $\sqrt{ }$ & \\
\hline City-year & $\sqrt{ }$ & & $\checkmark$ & $\sqrt{ }$ & & $\checkmark$ \\
\hline City-distance & & $\checkmark$ & $\sqrt{ }$ & & $\sqrt{ }$ & $\sqrt{ }$ \\
\hline$N(' 000)$ & 65 & 65 & 65 & 65 & 65 & 65 \\
\hline
\end{tabular}

$Z$ is the Bartik demand shifter, calculated per Equation 1, also see Table A2. All regressions include the vector $(d 1, d 2, d 3)$. Significance levels: $* * *-0.001 ; * *-0.01$; $^{*}$ $-0.05 ;+-0.1$.

Source: Decennial censuses and the American Community Survey, restricted use data. 
Table 5: The Effects of FT on Housing Values: OLS

\begin{tabular}{|c|c|c|c|c|c|c|}
\hline & (1) & $(2)$ & $(3)$ & $(4)$ & $(5)$ & (6) \\
\hline & \multicolumn{6}{|c|}{ Four-year college or more } \\
\hline & \multicolumn{3}{|c|}{$40+$ hours $-F T(40, B A+)$} & \multicolumn{3}{|c|}{$50+$ hours $-F T(50, B A+)$} \\
\hline$F T$ & $\begin{array}{c}1.829 * * * \\
{[0.167]}\end{array}$ & $\begin{array}{c}2.037^{* * *} \\
{[0.164]}\end{array}$ & $\begin{array}{c}2.200^{* * *} \\
{[0.227]}\end{array}$ & $\begin{array}{c}4.003^{* * *} \\
{[0.371]}\end{array}$ & $\begin{array}{c}4.320^{* * *} \\
{[0.325]}\end{array}$ & $\begin{array}{c}4.408^{* * *} \\
{[0.388]}\end{array}$ \\
\hline \multicolumn{7}{|l|}{$F T \times$} \\
\hline \multirow[t]{2}{*}{ dist } & & $-0.0170^{*}$ & -0.0486 & & $-0.0260^{*}$ & -0.0446 \\
\hline & & {$[0.00686]$} & {$[0.0387]$} & & {$[0.0124]$} & {$[0.0781]$} \\
\hline \multirow[t]{2}{*}{$d i s t^{2}$} & & & 0.00103 & & & 0.000618 \\
\hline & & & {$[0.00106]$} & & & {$[0.00224]$} \\
\hline \multirow[t]{3}{*}{$R^{2}$} & 0.475 & 0.475 & 0.476 & 0.488 & 0.488 & 0.489 \\
\hline & \multicolumn{6}{|c|}{ Graduate degree } \\
\hline & $40+$ ho & $r s-F T(4)$ & $M A+)$ & $50+$ ho & $\mathrm{rs}-F T(5)$ & $M A+)$ \\
\hline \multirow[t]{2}{*}{$F T$} & $3.502^{* * *}$ & $3.635^{* * *}$ & $3.861^{* * *}$ & $6.733^{* * *}$ & $6.740^{* * *}$ & $6.933^{* * *}$ \\
\hline & {$[0.340]$} & {$[0.335]$} & {$[0.435]$} & {$[0.651]$} & {$[0.625]$} & {$[0.813]$} \\
\hline \multicolumn{7}{|l|}{$F T \times$} \\
\hline \multirow[t]{2}{*}{ dist } & & -0.0115 & -0.0564 & & -0.00123 & -0.0426 \\
\hline & & {$[0.0163]$} & {$[0.0764]$} & & {$[0.0320]$} & {$[0.154]$} \\
\hline \multirow[t]{2}{*}{$d i s t^{2}$} & & & 0.00148 & & & 0.00140 \\
\hline & & & {$[0.00203]$} & & & {$[0.00426]$} \\
\hline$R^{2}$ & 0.475 & 0.475 & 0.476 & 0.480 & 0.480 & 0.480 \\
\hline \multicolumn{7}{|l|}{ Fixed effects: } \\
\hline City-year & $\checkmark$ & $\sqrt{ }$ & $\checkmark$ & $\sqrt{ }$ & $\sqrt{ }$ & $\sqrt{ }$ \\
\hline City-distance & $\sqrt{ }$ & $\sqrt{ }$ & $\sqrt{ }$ & $\sqrt{ }$ & $\sqrt{ }$ & $\sqrt{ }$ \\
\hline$N(' 000)$ & 65 & 65 & 65 & 65 & 65 & 65 \\
\hline
\end{tabular}

Specifications including interactions also include all main effects in levels.

Significance levels: $* * *-0.001 ; * *-0.01{ }^{*}{ }^{*}-0.05 ;+-0.1$.

Source: Decennial censuses and the American Community Survey, restricted use data. 
Table 6: The Effects of FT on Housing Values: IV

\begin{tabular}{|c|c|c|c|c|c|c|}
\hline & (1) & $(2)$ & $(3)$ & $(4)$ & $(5)$ & (6) \\
\hline \multirow[b]{3}{*}{$F T$} & \multicolumn{6}{|c|}{ Four-year college or more } \\
\hline & \multicolumn{3}{|c|}{$40+$ hours $-F T(40, B A+)$} & \multicolumn{3}{|c|}{$50+$ hours $-F T(50, B A+)$} \\
\hline & $\begin{array}{c}2.007+ \\
{[1.201]}\end{array}$ & $\begin{array}{c}5.010^{* * *} \\
{[1.049]}\end{array}$ & $\begin{array}{c}4.526^{* * *} \\
{[1.137]}\end{array}$ & $\begin{array}{c}6.017^{* * *} \\
{[0.889]}\end{array}$ & $\begin{array}{c}7.039^{* * *} \\
{[0.810]}\end{array}$ & $\begin{array}{c}6.704^{* * *} \\
{[0.996]}\end{array}$ \\
\hline \multicolumn{7}{|l|}{$F T \times$} \\
\hline dist & & $\begin{array}{c}-0.198^{* * *} \\
{[0.0204]}\end{array}$ & $\begin{array}{c}-0.380^{* *} \\
{[0.139]}\end{array}$ & & $\begin{array}{c}-0.408^{* * *} \\
{[0.0467]}\end{array}$ & $\begin{array}{c}-0.767^{*} \\
{[0.352]}\end{array}$ \\
\hline$d i s t^{2}$ & & & $\begin{array}{c}0.00617 \\
{[0.00437]}\end{array}$ & & & $\begin{array}{c}0.0119 \\
{[0.0110]}\end{array}$ \\
\hline \multicolumn{7}{|l|}{ IV tests: } \\
\hline K-P $L M$ test $(p)$ & 0.00615 & 0.00247 & 0.000493 & 0.0163 & 0.00716 & 0.00203 \\
\hline C-D Wald stat. & $77.35^{b_{5}, s_{10}}$ & $79.06^{b_{5}, s_{10}}$ & $38.40^{b_{5}}$ & $169.4^{b_{5}, s_{10}}$ & $148.3^{b_{5}, s_{10}}$ & $46.53^{b_{5}}$ \\
\hline K-P Wald stat. & $20.00^{b_{5}, s_{15}}$ & $19.35^{b_{5}, s_{10}}$ & $11.66^{b_{5}}$ & $7.615^{b_{20}}$ & $8.819^{b_{10}, s_{15}}$ & $10.39^{b_{5}}$ \\
\hline \multirow[t]{3}{*}{ Overid. test $(p)$} & 0.0456 & 0.244 & . & 0.0299 & 0.345 & . \\
\hline & \multicolumn{6}{|c|}{ Graduate degree } \\
\hline & $40+$ hol & Irs $-F T(40$, & $M A+)$ & $50+$ ho & $\operatorname{ars}-F T(50$ & $M A+)$ \\
\hline \multirow[t]{2}{*}{$F T$} & 3.212 & $11.12^{* * *}$ & $10.47^{* * *}$ & $13.15^{* * *}$ & $15.24^{* * *}$ & $14.77^{* * *}$ \\
\hline & {$[2.605]$} & {$[2.407]$} & {$[2.486]$} & {$[1.973]$} & [1.803] & {$[2.141]$} \\
\hline \multicolumn{7}{|l|}{$F T \times$} \\
\hline \multirow[t]{2}{*}{ dist } & & $-0.509 * * *$ & $-1.014^{* *}$ & & $-0.928^{* * *}$ & $-1.709 *$ \\
\hline & & {$[0.0590]$} & {$[0.387]$} & & {$[0.115]$} & {$[0.823]$} \\
\hline \multirow[t]{2}{*}{$d i s t^{2}$} & & & 0.0172 & & & 0.0260 \\
\hline & & & {$[0.0118]$} & & & {$[0.0254]$} \\
\hline \multicolumn{7}{|l|}{ IV tests: } \\
\hline $\mathrm{K}-\mathrm{P} L M$ test $(p)$ & 0.00438 & 0.00182 & 0.000400 & 0.0164 & 0.00263 & 0.00127 \\
\hline C-D Wald STAT. & 63.02 & 63.65 & 33.45 & 111.2 & 97.07 & 34.76 \\
\hline K-P Wald STAT. & 30.01 & 20.77 & 14.32 & 10.05 & 11.43 & 14.27 \\
\hline Overid. test $(p)$ & 0.0589 & 0.204 & . & 0.0406 & 0.350 & . \\
\hline \multicolumn{7}{|l|}{ Fixed effects: } \\
\hline City-year & $\sqrt{ }$ & $\sqrt{ }$ & $\sqrt{ }$ & $\sqrt{ }$ & $\sqrt{ }$ & $\sqrt{ }$ \\
\hline City-distance & $\checkmark$ & $\sqrt{ }$ & $\sqrt{ }$ & $\checkmark$ & $\checkmark$ & $\checkmark$ \\
\hline$N(' 000)$ & 65 & 65 & 65 & 65 & 65 & 65 \\
\hline
\end{tabular}

Notes on separate page. 
Notes to Table 6 .

$Z$ is the Bartik demand shifter, calculated per Equation 1, also see Table A2. Throughout, the three instruments are $Z \times d 1, Z \times d 2, Z \times d 3$. Specifications including interactions also include all main effects in levels.

K-P $L M$ test $(p)$ corresponds to the p-value of the Kleinbergen-Paap LM test. The null hypothesis is that the structural equation is underidentified (i.e., the rank condition fails).

C-D Wald stat and K-P Wald stat are the Cragg-Donald and Kleibergen-Paap Wald statistics for testing weak identification. In both cases, the critical values are the Stock and Yogo [2005] critical values initially tabulated for the C-D Wald stat, see Table A4. We follow Baum [2007] and also apply the Stock and Yogo critical values to the K-P Wald stat (critical values for the K-P Wald stat do not exist). In each case, we specify whether the test statistics rejects the null hypothesis (at the $5 \%$ level) that the bias of of the IV estimates exceeds the OLS bias by 5, 10, 20 and 30 percent (b5, b10, b20, b30), and whether test statistics rejects the null hypothesis (at the 5\% level) that the size of the test is greater than 10, 15, 20 and 25 percent (s20, s15, s20, s25). The critical values for the relative bias test cannot be computed for the case of 2 endogenous and 3 instruments and for 3 endogenous and 3 instruments, and we use the more conservative critical values for the case of 2 endogenous and 4 instruments and 3 endogenous and 5 instruments, see Stock and Yogo [2005] and Table A4. Critical values for the size test with 3 or more endogenous have not been computed.

Overid. test $(p)$ corresponds to the $p$-value of the test of the overidentifying restrictions. The null hypothesis is that the instruments are valid instruments.

Significance levels: *** $-0.001 ; * *-0.01 ; *-0.05 ;+-0.1$.

Source: Decennial censuses and the American Community Survey, restricted use data. 
Table 7: The Effects of FT on Housing Values: IV, continued

\begin{tabular}{|c|c|c|c|c|c|c|}
\hline & (1) & $(2)$ & $(3)$ & (4) & (5) & (6) \\
\hline & \multicolumn{6}{|c|}{ Sample: } \\
\hline & \multicolumn{3}{|c|}{ Cross-section } & \multicolumn{3}{|c|}{ Panel } \\
\hline & Crime, high ${ }^{a}$ & Crime, low ${ }^{a}$ & not $\mathrm{NYC}^{b}$ & All & Black, low ${ }^{c}$ & Black, high ${ }^{c}$ \\
\hline \multirow[b]{2}{*}{$F T$} & \multicolumn{6}{|c|}{$\begin{array}{c}\text { Dependent variable: } \\
40+\text { hours, four-year college or more }-F T(40, B A+)\end{array}$} \\
\hline & $\begin{array}{c}5.957^{* * *} \\
{[1.262]}\end{array}$ & $\begin{array}{c}3.903^{* * *} \\
{[1.149]}\end{array}$ & $\begin{array}{c}3.570^{* * *} \\
{[0.969]}\end{array}$ & $\begin{array}{c}5.511^{* * *} \\
{[1.131]}\end{array}$ & $\begin{array}{c}5.848^{* * *} \\
{[1.021]}\end{array}$ & $\begin{array}{c}5.197^{* * *} \\
{[1.314]}\end{array}$ \\
\hline$F T \times d i s t$ & $\begin{array}{c}-0.201^{* * *} \\
{[0.0250]}\end{array}$ & $\begin{array}{c}-0.185^{* * *} \\
{[0.0294]}\end{array}$ & $\begin{array}{c}-0.178^{* * *} \\
{[0.0211]}\end{array}$ & $\begin{array}{c}-0.201^{* * *} \\
{[0.0256]}\end{array}$ & $\begin{array}{c}-0.172^{* * *} \\
{[0.0319]}\end{array}$ & $\begin{array}{c}-0.244^{* * *} \\
{[0.0429]}\end{array}$ \\
\hline \multicolumn{7}{|l|}{ IV tests: ${ }^{d}$} \\
\hline $\mathrm{K}-\mathrm{P} L M$ test $(p)$ & 0.105 & 0.00938 & 0.00232 & 0.0166 & 0.168 & 0.0356 \\
\hline C-D Wald stat. & 53.96 & 25.45 & 44.53 & 391.6 & 153.3 & 205.8 \\
\hline K-P Wald stat. & 6.975 & 75.33 & 12.87 & 9.31 & 5.58 & 9.358 \\
\hline Overid. test $(p)$ & 0.18 & 0.717 & 0.332 & 0.345 & 0.102 & 0.529 \\
\hline & \multicolumn{6}{|c|}{$50+$ hours, four-year college or more $-F T(50, B A+)$} \\
\hline$F T$ & $\begin{array}{c}7.041^{* * *} \\
{[0.813]}\end{array}$ & $\begin{array}{c}7.497^{* *} \\
{[2.330]}\end{array}$ & $\begin{array}{c}6.407^{* * *} \\
{[1.605]}\end{array}$ & $\begin{array}{c}7.241^{* * *} \\
{[0.811]}\end{array}$ & $\begin{array}{c}6.626^{* * *} \\
{[1.146]}\end{array}$ & $\begin{array}{c}7.517^{* * *} \\
{[1.070]}\end{array}$ \\
\hline$F T \times d i s t$ & $\begin{array}{c}-0.399^{* * *} \\
{[0.0506]}\end{array}$ & $\begin{array}{c}-0.426^{* * *} \\
{[0.0749]}\end{array}$ & $\begin{array}{c}-0.404^{* * *} \\
{[0.0626]}\end{array}$ & $\begin{array}{c}-0.423^{* * *} \\
{[0.0499]}\end{array}$ & $\begin{array}{c}-0.346^{* * *} \\
{[0.0536]}\end{array}$ & $\begin{array}{c}-0.592^{* * *} \\
{[0.138]}\end{array}$ \\
\hline \multicolumn{7}{|l|}{ IV tests: ${ }^{d}$} \\
\hline $\mathrm{K}-\mathrm{P} L M$ test $(p)$ & 0.0665 & 0.00764 & 0.00717 & 0.0386 & 0.242 & 0.0643 \\
\hline C-D Wald stat. & 116.4 & 25.58 & 59.01 & 602.8 & 325.5 & 218.3 \\
\hline K-P Wald stat. & 22.58 & 34.61 & 8.896 & 4.641 & 3.731 & 5.041 \\
\hline Overid. test $(p)$ & 0.0954 & 0.529 & 0.504 & 0.276 & 0.0945 & 0.433 \\
\hline & \multicolumn{6}{|c|}{$40+$ hours, graduate degree $-F T(40, M A+)$} \\
\hline$F T$ & $\begin{array}{c}13.85^{* * *} \\
{[2.801]}\end{array}$ & $\begin{array}{c}8.345^{* * *} \\
{[2.307]}\end{array}$ & $\begin{array}{c}7.620^{* * *} \\
{[2.252]}\end{array}$ & $\begin{array}{c}12.01^{* * *} \\
{[1.873]}\end{array}$ & $\begin{array}{c}13.78^{* * *} \\
{[1.744]}\end{array}$ & $\begin{array}{c}11.03^{* * *} \\
{[2.484]}\end{array}$ \\
\hline$F T \times d i s t$ & $\begin{array}{c}-0.556^{* * *} \\
{[0.0732]}\end{array}$ & $\begin{array}{c}-0.442^{* * *} \\
{[0.0838]}\end{array}$ & $\begin{array}{c}-0.454^{* * *} \\
{[0.0616]}\end{array}$ & $\begin{array}{c}-0.527^{* * *} \\
{[0.0667]}\end{array}$ & $\begin{array}{c}-0.467^{* * *} \\
{[0.0739]}\end{array}$ & $\begin{array}{c}-0.674^{* * *} \\
{[0.138]}\end{array}$ \\
\hline IV tests: ${ }^{d}$ & & & & & & \\
\hline $\mathrm{K}-\mathrm{P} L M$ test $(p)$ & 0.116 & 0.00693 & 0.00206 & 0.02 & 0.287 & 0.0296 \\
\hline C-D Wald stat. & 43.54 & 22.7 & 36.28 & 267.9 & 95.28 & 122.8 \\
\hline K-P Wald stat. & 6.382 & 41.89 & 13.8 & 5.944 & 2.574 & 8.915 \\
\hline Overid. test $(p)$ & 0.136 & 0.628 & 0.297 & 0.332 & 0.15 & 0.486 \\
\hline
\end{tabular}


Table 8: The Effects of FT on Housing Values: IV, continued

\begin{tabular}{|c|c|c|c|c|c|c|}
\hline & (1) & $(2)$ & $(3)$ & $(4)$ & $(5)$ & (6) \\
\hline & \multicolumn{6}{|c|}{ Sample: } \\
\hline & \multicolumn{3}{|c|}{ Cross-section } & \multicolumn{3}{|c|}{ Panel } \\
\hline & Crime, high $^{a}$ & Crime, low ${ }^{a}$ & not $\mathrm{NYC}^{b}$ & All & Black, low ${ }^{c}$ & Black, high ${ }^{c}$ \\
\hline \multirow{4}{*}{$F T$} & \multicolumn{6}{|c|}{ Dependent variable: } \\
\hline & \multicolumn{6}{|c|}{$50+$ hours, graduate degree $-F T(50, M A+)$} \\
\hline & $15.95^{* * *}$ & $15.21^{* * *}$ & $13.05^{* * *}$ & $15.32^{* * *}$ & $14.83^{* * *}$ & $15.38^{* * *}$ \\
\hline & {$[1.776]$} & {$[4.498]$} & {$[3.286]$} & {$[1.554]$} & {$[2.150]$} & {$[2.468]$} \\
\hline \multirow[t]{2}{*}{$F T \times d i s t$} & $-0.929 * * *$ & $-0.909^{* * *}$ & $-0.918^{* * *}$ & $-0.963^{* * *}$ & $-0.792^{* * *}$ & $-1.453^{* * *}$ \\
\hline & {$[0.131]$} & {$[0.204]$} & {$[0.167]$} & {$[0.118]$} & {$[0.117]$} & {$[0.380]$} \\
\hline \multicolumn{7}{|l|}{ IV tests: ${ }^{d}$} \\
\hline $\mathrm{K}-\mathrm{P} L M$ test $(p)$ & 0.0682 & 0.00496 & 0.00271 & 0.0187 & 0.28 & 0.0624 \\
\hline C-D Wald stat. & 75.64 & 19.91 & 40.28 & 345.1 & 175.6 & 113.5 \\
\hline K-P Wald stat. & 17.37 & 21.87 & 11.32 & 4.783 & 2.686 & 4.894 \\
\hline Overid. test $(p)$ & 0.102 & 0.468 & 0.54 & 0.303 & 0.111 & 0.466 \\
\hline \multicolumn{7}{|l|}{ Fixed effects: } \\
\hline City-year & $\sqrt{ }$ & $\sqrt{ }$ & $\sqrt{ }$ & $\checkmark$ & $\sqrt{ }$ & $\checkmark$ \\
\hline City-distance & $\sqrt{ }$ & $\sqrt{ }$ & $\sqrt{ }$ & & & \\
\hline Tract & & & & $\sqrt{ }$ & $\sqrt{ }$ & $\sqrt{ }$ \\
\hline$N(' 000)$ & $65 / 2$ & $65 / 2$ & 53 & 48 & $48 / 2$ & $48 / 2$ \\
\hline
\end{tabular}

Notes to Table 8.

Throughout, the three instruments are $Z \times d 1, Z \times d 2, Z \times d 3$. Specifications including interactions also include all main effects in levels.

${ }^{a}$ High and low crime samples split cities in the cross sectional sample according to the decline in crime, see Table A1.

${ }^{b}$ Not NYC removes New York City from the cross sectional sample.

${ }^{c}$ High and low Black samples split tracts in the tract-panel sample according to their 1980 percent blacks in the tract.

${ }^{d}$ See notes to Table 6.

Significance levels: $* * *-0.001 ; * *-0.01 ; *-0.05 ;+-0.1$.

Source: Decennial censuses and the American Community Survey, restricted use data. 


\section{APPENDIX}

\section{Figures}

Figure A1: Full time (40h/week)

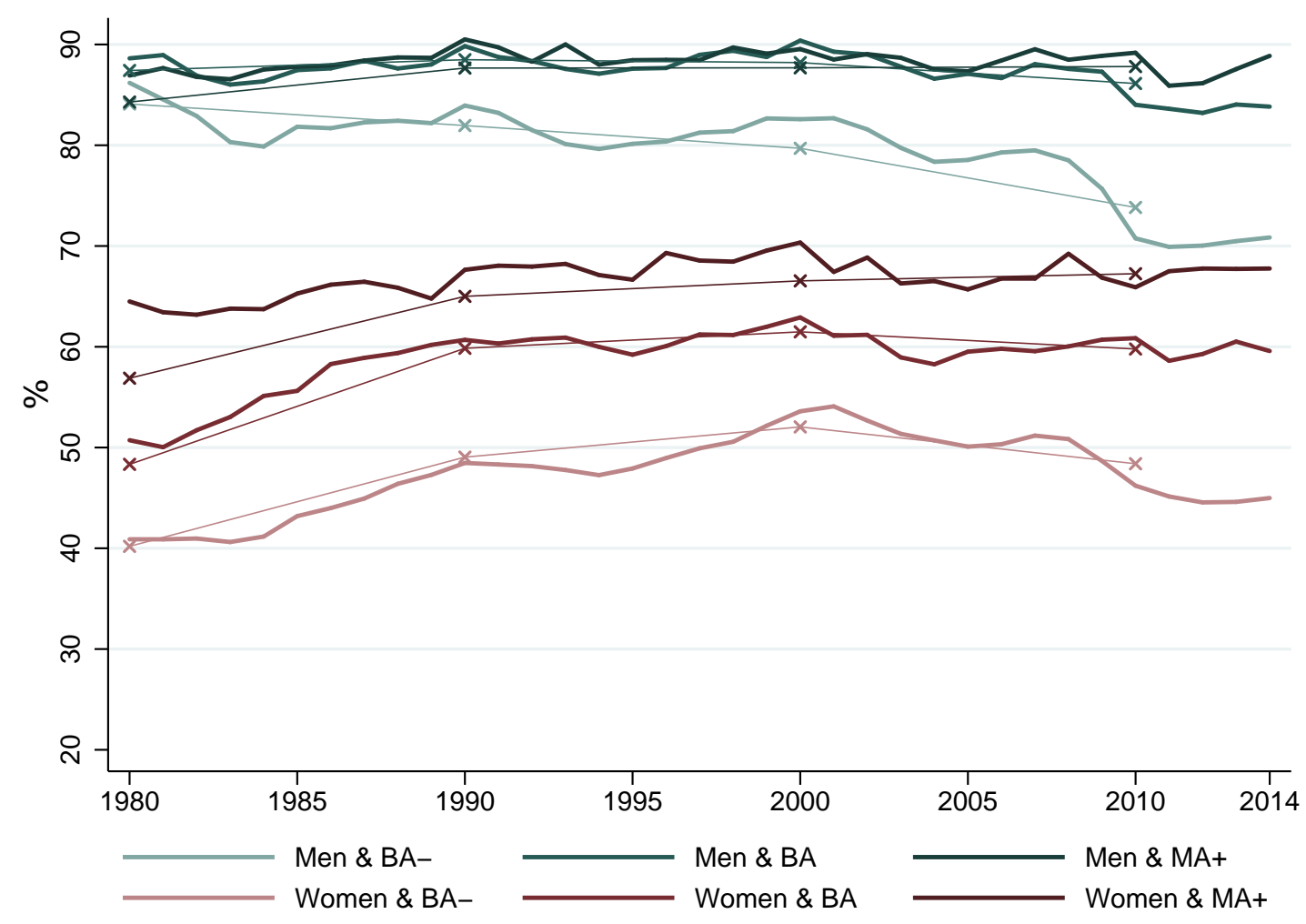

Note: Men and women ages 25-55.

Source: Decennial censuses, integrated public use micro data series (IPUMS). 
Figure A2: Full time (50h/week)

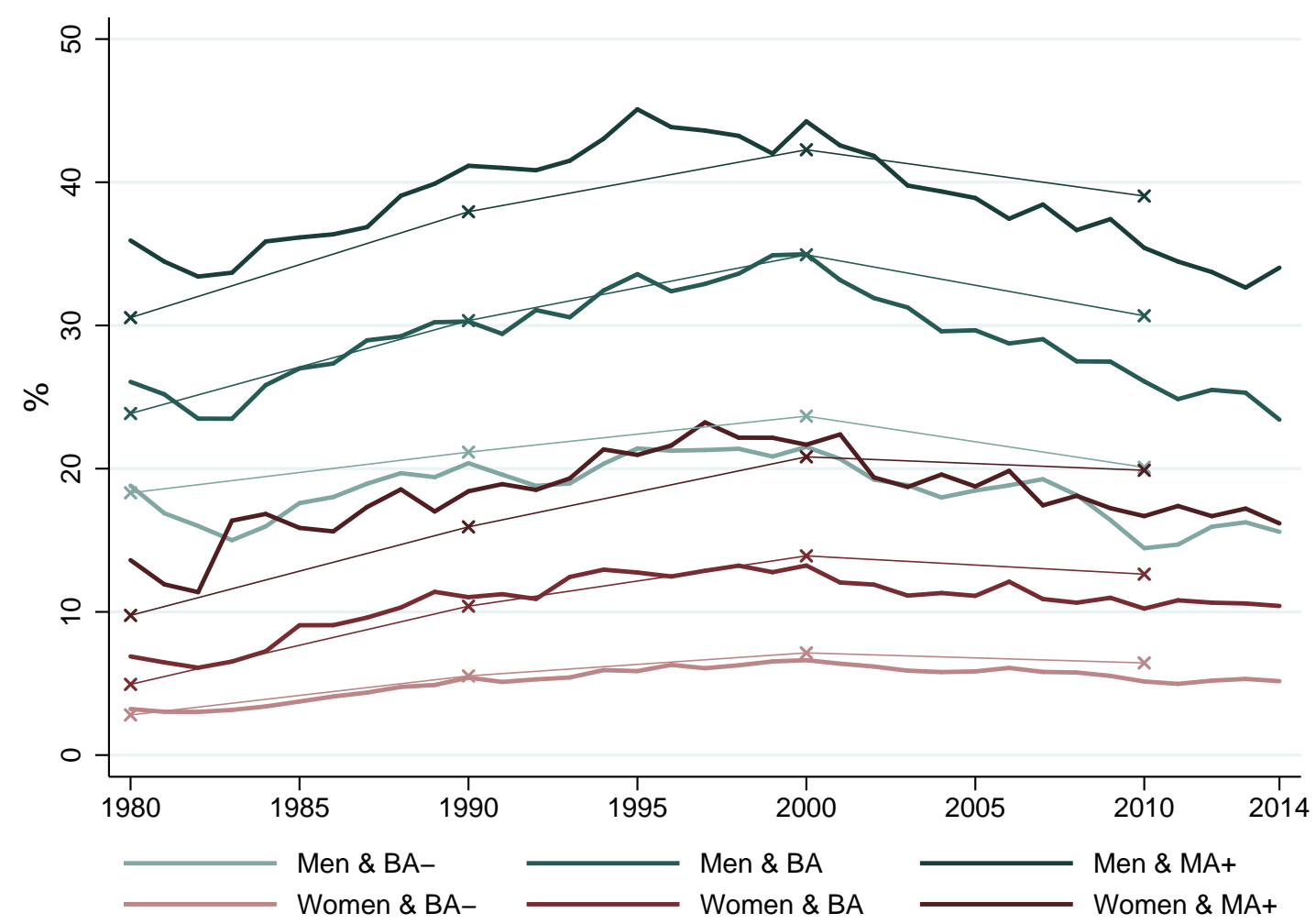

Note: Men and women ages 25-55.

Source: Decennial censuses, integrated public use micro data series (IPUMS). 
Figure A3: \% adults 25-55, unskilled and full time, by location
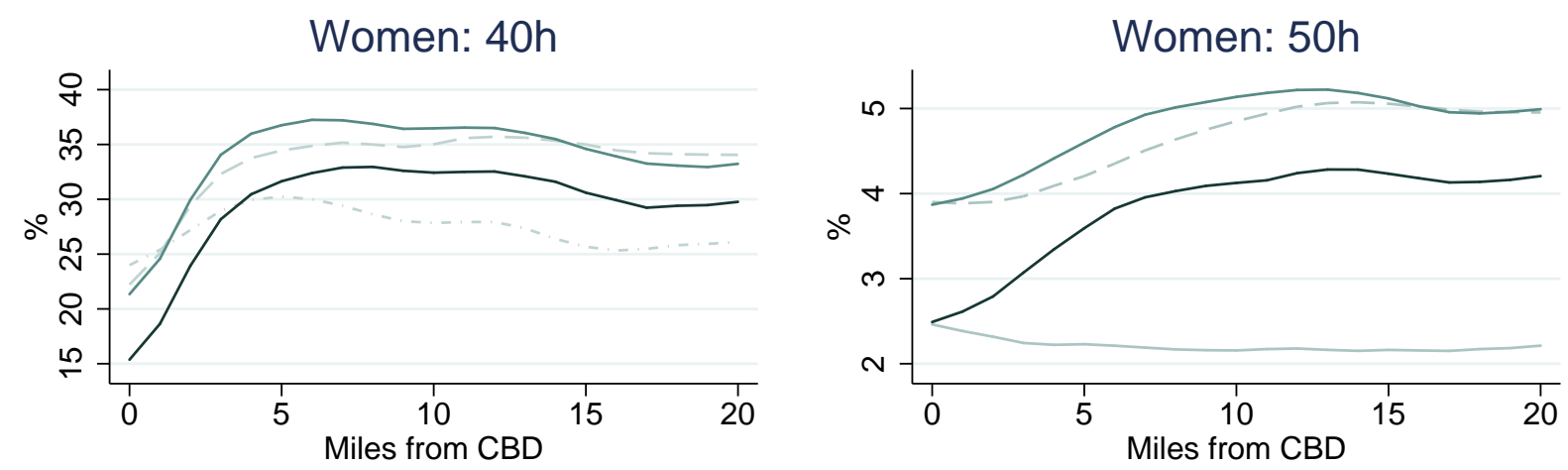

Men: 40h
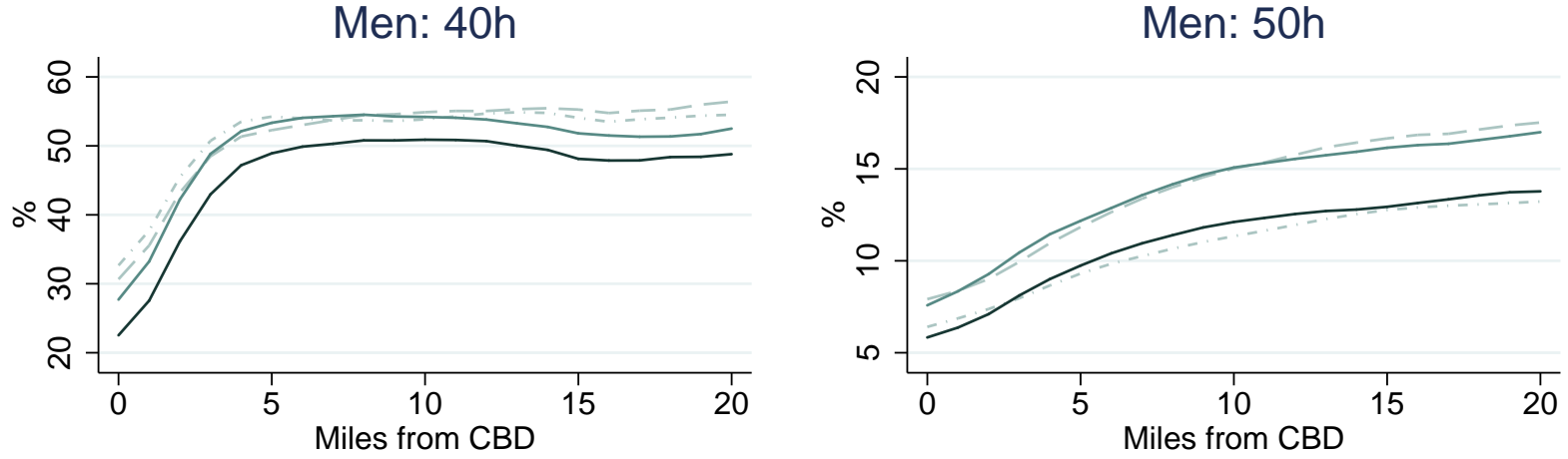

\section{$1980----1990-2000 \longrightarrow 2010$}

Source: Decennial censuses and the American Community Survey, restricted use data. 
Figure A4: Private school by residence location, primary and middle school

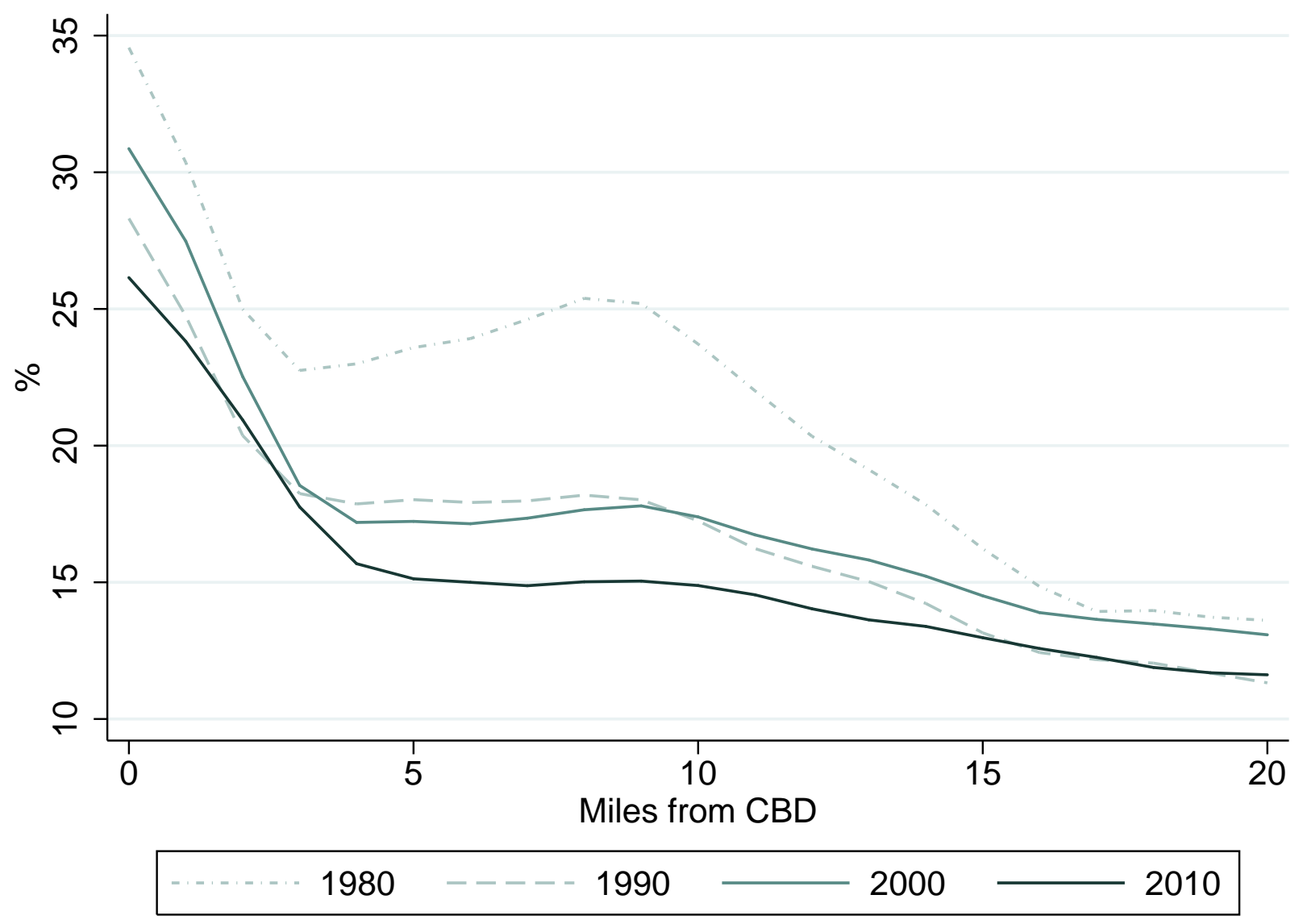

Universe: Children 6 -12 residing $x=0,1, \ldots 18,19,20-35$ miles from the CBD. Source: Decennial censuses and the American Community Survey, restricted use data. 
Figure A5: Private school by residence location, high school

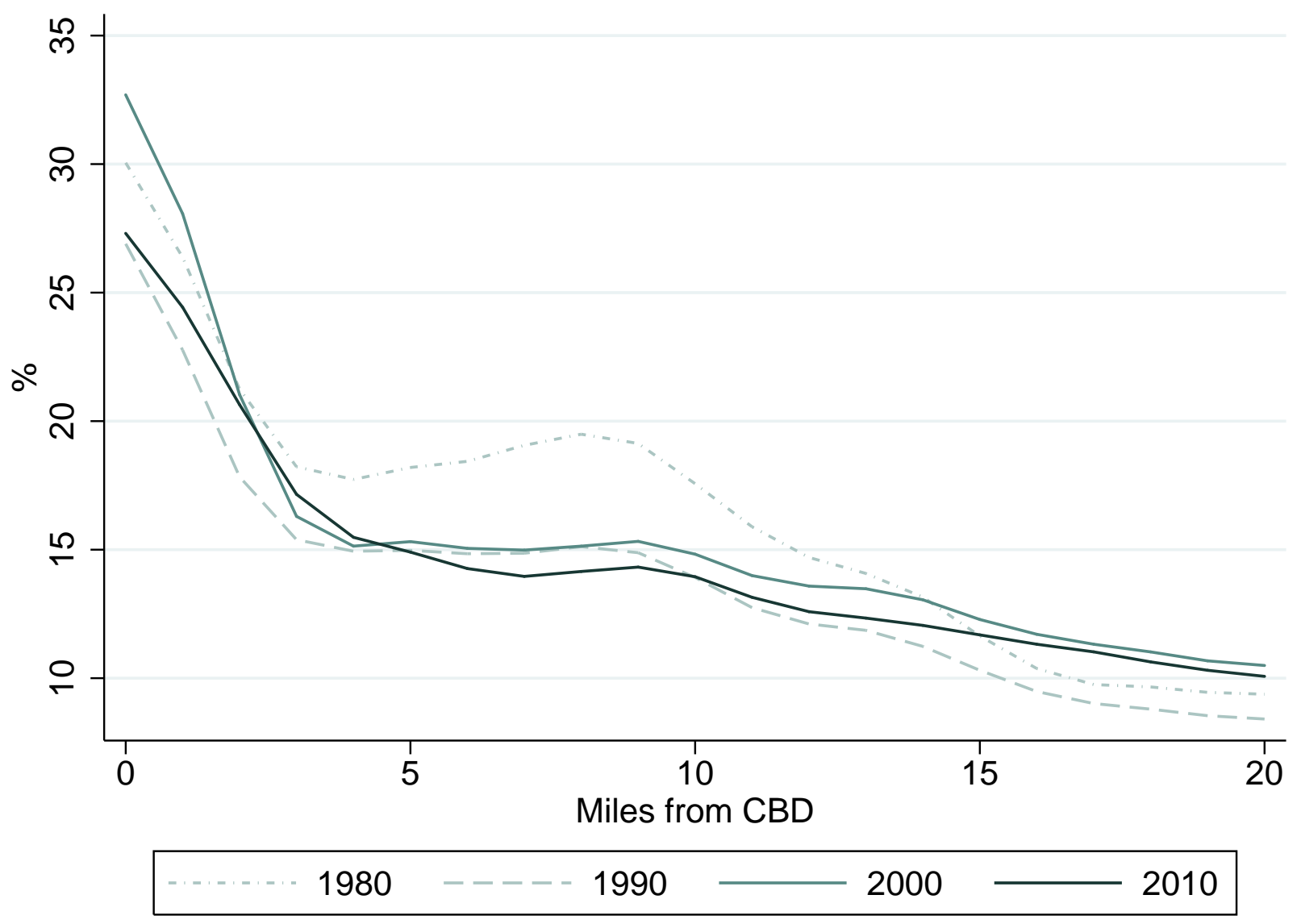

Universe: Children 13-18 residing $x=0,1, \ldots 18,19,20-35$ miles from the CBD.

Source: Decennial censuses and the American Community Survey, restricted use data. 
Table A1: Change in Violent Crime 1986-2012 - Crime

\begin{tabular}{ll}
\hline \hline High Crime Reduction Cities & \\
\hline New Orleans & -.64 \\
New York City & -.60 \\
Boston & -.55 \\
Los Angeles County & -.54 \\
Detroit & -.42 \\
Baltimore City & -.41 \\
Dallas & -.41 \\
San Francisco & -.39 \\
Low Crime Reduction Cities & \\
\hline St. Louis & -.34 \\
Jacksonville & -.28 \\
City Of Fort Worth & -.28 \\
Washington Metropolitan & -.26 \\
San Diego County Sheriff & -.18 \\
El Paso County Sheriff & -.18 \\
Cleveland & -.17 \\
San Jose & .02 \\
Philadelphia & .10 \\
Columbus* & .18 \\
Memphis & .18 \\
Phoenix & .25 \\
San Antonio & .28 \\
Houston & .31 \\
Austin & .44 \\
Milwaukee & .91 \\
Indianapolis & 1.15 \\
Chicago & $n . a$. \\
Charlotte & $n . a$ \\
\hline The entry & Cor \\
\hline
\end{tabular}

$\bar{*}$ The entry for Columbus is for the period 1986-2011.

Violent crimes include murder, rape, robbery, aggravated assault. For a detailed description, see http://www.ucrdatatool.gov/offenses.cfm.

Source: Uniform Crime Report http://www.ucrdatatool.gov/Search/Crime/ Local/TrendsInOneVarLarge.cfm 


\section{Bartik}

We group industries into 41 categories using the 1990 industry classification available in IPUMS. Those groups are detailed in Table A3. In the preliminary analysis we also used a more aggregate grouping into seven industries, the results were very similar, but we favor the more disaggregate grouping because of the reduction in within-group industry heterogeneity.

Table A2: Bartik, Base Year 1970 - TBartik7A

\begin{tabular}{|c|c|c|c|c|c|}
\hline \multicolumn{6}{|c|}{ Sorted alphabetically } \\
\hline & & & & & Center point \\
\hline City & 1980 & 1990 & 2000 & 2010 & Central Business District (CBD) \\
\hline Austin & 0.169 & 0.259 & 0.320 & 0.350 & Texas Capitol \\
\hline Baltimore & 0.110 & 0.169 & 0.206 & 0.223 & W. Lexington $\times$ Park Ave. \\
\hline Boston & 0.144 & 0.226 & 0.277 & 0.298 & South Station \\
\hline Charlotte & 0.102 & 0.162 & 0.192 & 0.206 & Charlotte Convention Center \\
\hline Chicago & 0.110 & 0.175 & 0.214 & 0.229 & LaSalle $\times$ W. Congress Parkway \\
\hline Cleveland & 0.102 & 0.162 & 0.196 & 0.212 & Soldiers' and Sailors' Monument \\
\hline Columbus & 0.126 & 0.197 & 0.242 & 0.262 & E. Long Street $\times$ Route 3 \\
\hline Dallas & 0.122 & 0.196 & 0.232 & 0.251 & Dallas Convention center \\
\hline Detroit & 0.090 & 0.145 & 0.171 & 0.186 & Grand Circus Park \\
\hline El Paso & 0.112 & 0.170 & 0.211 & 0.230 & El Paso Art Institute \\
\hline Fort Worth & 0.122 & 0.196 & 0.232 & 0.251 & Fort Worth Convention Center \\
\hline Houston & 0.137 & 0.209 & 0.243 & 0.266 & Houston Center \\
\hline Indianapolis & 0.093 & 0.147 & 0.177 & 0.191 & Monument Circle \\
\hline Jacksonville & 0.094 & 0.148 & 0.178 & 0.194 & Bank of America Tower \\
\hline Los Angeles & 0.126 & 0.200 & 0.242 & 0.260 & Pershing Square \\
\hline Memphis & 0.091 & 0.144 & 0.176 & 0.190 & Beale St. $\times$ Riverside Drive \\
\hline Milwaukee & 0.102 & 0.159 & 0.192 & 0.207 & Milwaukee County Court House \\
\hline New Orleans & 0.112 & 0.169 & 0.196 & 0.216 & New Orleans Morial Convention Center \\
\hline New York & 0.136 & 0.217 & 0.266 & 0.286 & Rockefeller Center \\
\hline Philadelphia & 0.105 & 0.165 & 0.202 & 0.218 & City Hall \\
\hline Phoenix & 0.116 & 0.183 & 0.221 & 0.237 & Phoenix Convention Center \\
\hline Saint Louis & 0.103 & 0.163 & 0.197 & 0.213 & Federal Reserve \\
\hline San Antonio & 0.089 & 0.138 & 0.166 & 0.180 & Tower of the Americas \\
\hline San Diego & 0.125 & 0.196 & 0.240 & 0.259 & Horton Plaza \\
\hline San Francisco & 0.172 & 0.273 & 0.332 & 0.362 & Transamerica Pyramid \\
\hline San Jose & 0.163 & 0.253 & 0.312 & 0.330 & 1 Infinity Loop (Apple headquarters) \\
\hline Washington D.C. & 0.229 & 0.344 & 0.426 & 0.461 & White House \\
\hline
\end{tabular}


Table A2: Bartik, Base Year: 1970 - TBartik7D

\begin{tabular}{|c|c|c|c|c|c|}
\hline \multicolumn{6}{|c|}{ Sorted by 2010-1980 difference } \\
\hline City & 1980 & 1990 & 2000 & 2010 & 2010-1980 \\
\hline San Antonio & 0.089 & 0.138 & 0.166 & 0.180 & 0.091 \\
\hline Detroit & 0.090 & 0.145 & 0.171 & 0.186 & 0.097 \\
\hline Indianapolis & 0.093 & 0.147 & 0.177 & 0.191 & 0.098 \\
\hline Memphis & 0.091 & 0.144 & 0.176 & 0.190 & 0.099 \\
\hline Jacksonville & 0.094 & 0.148 & 0.178 & 0.194 & 0.100 \\
\hline Charlotte & 0.102 & 0.162 & 0.192 & 0.206 & 0.104 \\
\hline New Orleans & 0.112 & 0.169 & 0.196 & 0.216 & 0.104 \\
\hline Milwaukee & 0.102 & 0.159 & 0.192 & 0.207 & 0.105 \\
\hline Cleveland & 0.102 & 0.162 & 0.196 & 0.212 & 0.110 \\
\hline Saint Louis & 0.103 & 0.163 & 0.197 & 0.213 & 0.110 \\
\hline Baltimore & 0.110 & 0.169 & 0.206 & 0.223 & 0.113 \\
\hline Philadelphia & 0.105 & 0.165 & 0.202 & 0.218 & 0.113 \\
\hline El Paso & 0.112 & 0.170 & 0.211 & 0.230 & 0.118 \\
\hline Chicago & 0.110 & 0.175 & 0.214 & 0.229 & 0.119 \\
\hline Phoenix & 0.116 & 0.183 & 0.221 & 0.237 & 0.121 \\
\hline Dallas/Fort Worth & 0.122 & 0.196 & 0.232 & 0.251 & 0.129 \\
\hline Houston & 0.137 & 0.209 & 0.243 & 0.266 & 0.129 \\
\hline Los Angeles & 0.126 & 0.200 & 0.242 & 0.260 & 0.134 \\
\hline San Diego & 0.125 & 0.196 & 0.240 & 0.259 & 0.134 \\
\hline Columbus & 0.126 & 0.197 & 0.242 & 0.262 & 0.136 \\
\hline New York & 0.136 & 0.217 & 0.266 & 0.286 & 0.150 \\
\hline Boston & 0.144 & 0.226 & 0.277 & 0.298 & 0.154 \\
\hline San Jose & 0.163 & 0.253 & 0.312 & 0.330 & 0.167 \\
\hline Austin & 0.169 & 0.259 & 0.320 & 0.350 & 0.181 \\
\hline San Francisco & 0.172 & 0.273 & 0.332 & 0.362 & 0.190 \\
\hline Washington D.C. & 0.229 & 0.344 & 0.426 & 0.461 & 0.232 \\
\hline Mean & 0.122 & & & 0.250 & 0.128 \\
\hline
\end{tabular}


Table A3: 41-Industry Bartik - Ti41

\begin{tabular}{lll}
\hline \hline 1 & ind $\in[10,32]$ & agriculture \\
2 & ind $\in[40,50]$ & mining \\
3 & ind $=60$ & construction \\
4 & ind $\in[100,122]$ & manufacturing nondurable food \\
5 & ind $=130$ & manufacturing nondurable tobacco \\
6 & ind $\in[132,152]$ & manufacturing nondurable textiles \\
7 & ind $\in[160,172]$ & manufacturing nondurable paper, print and publish \\
8 & ind $\in[180,192]$ & manufacturing nondurable chemical \\
9 & ind $\in[200,201]$ & manufacturing nondurable petroleum \\
10 & ind $\in[210,212]$ & manufacturing nondurable rubber \\
11 & ind $\in[220,222]$ & manufacturing nondurable leather \\
12 & ind $\in[230,241]$ & manufacturing durable lumber \\
$13 \quad$ ind $=242$ & manufacturing durable furniture \\
14 & ind $\in[250,262]$ & manufacturing durable stone, glass \\
15 & ind $\in[270,301]$ & manufacturing durable metal \\
16 & ind $\in[310,332]$ & manufacturing durable machinery and computer \\
17 & ind $\in[340,350]$ & manufacturing durable equipment and supplies \\
18 & ind $\in[351,370]$ & manufacturing durable transportation equipment \\
19 & ind $\in[371,381]$ & manufacturing durable professional equipment \\
20 & ind $\in[391,392]$ & manufacturing durable other \\
21 & ind $\in[400,432]$ & transportation \\
22 & ind $\in[440,442]$ & communication \\
$23 \quad$ ind $\in[450,472]$ & utilities \\
$24 \quad$ ind $\in[500,532]$ & wholesale durable \\
25 & ind $\in[540,571]$ & wholesale nondurable \\
26 & ind $\in[580,691]$ & retail trade \\
27 & ind $\in[700,712]$ & finance \\
$28 \quad$ ind $\in[721,760]$ & business and repair \\
29 & ind $\in[761,791]$ & personal services \\
30 & ind $\in[800,810]$ & entertainment \\
31 & ind $\in[812,830]$ & prof office and clinics \\
32 & ind $\in[831,840]$ & hospitals \\
$33 \quad$ ind $=841$ & legal \\
$34 \quad$ ind $\in[842,861]$ & education and training \\
$35 \quad$ ind $\in[862,870]$ & care \\
36 & ind $\in[871,881]$ & services \\
37 & ind $=882$ & engineering, architectural, and surveying services \\
$38 \quad$ ind $=890$ & accounting, auditing, and bookkeeping services \\
39 & ind $=891$ & research, development, and testing services \\
40 & ind $=892$ & management and public relations services \\
41 & ind $\in[900,932]$ & public administration \\
\hline \hline & &
\end{tabular}


Table A4: Threshold values for Cragg-Donald and Kleibergen-Paap Wald statistics

\begin{tabular}{lccc}
\hline \hline & $(1)$ & $(2)$ & $(3)$ \\
Endogenous & 1 & 2 & 3 \\
Exogenous & 3 & $4^{a}$ & $5^{b}$ \\
\hline Stock-Yogo TSLS Bias & & & \\
0.05 & 13.91 & 11.04 & 9.53 \\
0.10 & 9.08 & 7.56 & 6.61 \\
0.20 & 6.46 & 5.57 & 4.99 \\
0.30 & 5.39 & 4.73 & 4.30 \\
Stock-Yogo TSLS Size & & & \\
0.10 & 22.30 & 13.43 & \\
0.15 & 12.83 & 8.18 & \\
0.20 & 9.54 & 6.40 & \\
0.25 & 7.80 & 5.45 & \\
\hline \hline
\end{tabular}

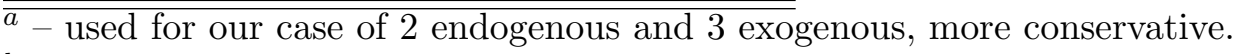

$b$ - used for our case of 3 endogenous and 3 exogenous, more conservative.

Source: Stock and Yogo [2005, table 5.1 and 5.2]. 


\section{V.1 Variable Construction}

PRICE 2-3 Bedroom single-family Home The decennial censuses and the ACS ask the owner of owner-occupied single-family homes the estimated value of the value of their home. While self-reported assessments of values, we will refer to them as housing prices.

In order to obtain numbers that are close to market prices, we restrict the sample to those who moved in within the last ten years, on the assumption that homes that owners of more recently bought and sold units would be more knowledgeable about price developments than those with longer tenure.

To obtain a price that refers to comparable units while preserving sample size, we focus on two or three bedroom single-family homes. Housing prices are given in intervals and the bracket values vary across the years. Therefore, we focus on the median bracket value. For tracts where the median bracket is the top code, we assign the dollar value that would be the mean if the top bracket had had the same range as the penultimate bracket. For instance, if the penultimate bracket ranged from 800 thousand to 1 million, and 1 million and above were the top bracket, we would give houses in the top bracket a 1.1 million dollar valuation. We chose this rule because it is conservative and if anything result in an underestimate of the price increases close to the CBD.

We focus on the median house price in the tract. Top coding is our reason for focusing on the median rather than a more selective percentile.

In our main specification, we impute a value that is the same distance to the top-code threshold as the immediately preceding midpoint value. For instance, if the top bracket is $800-1000$, and values above 1000 are top coded, we assign the value 1100 to the top code. This method is conservative if the housing price distribution, like the wealth and income distributions, is right skewed.

We have also tried alternative top codings, including simply imputing the threshold value. Our qualitative results were not sensitive to the variation tried.

For the study period 1980-2010, our measure shows a 30 percent increase in constant dollars, a rise largely inline with the Case-Shiller national index's rise of 26 percent. The Case-Shiller national index went from 43.44 to 145.0, and the CPI from 100 to 264, yielding a constant dollar housing price increase of 26 percent $\left(=\frac{145}{43.44} \times \frac{100}{264}-1\right)$.

Another benchmark is offered by the Census Bureau's constant price index for new-family homes sold rose from $\$ 72$ to $\$ 272$ thousand, current dollars. In constant dollars, the increase was 30 percent $\left(=\frac{261}{76} \times \frac{100}{264}-1\right)$. https : //www. census . gov/const/www/constpriceindex_excel.html

We use the Consumer Price Index (CPI) to deflate housing prices. A theoretical concern is that housing accounts for some 40 percent of the CPI and therefore a price index that excluded housing would be preferable, for instance the food 
price index. Conveniently, the food price index moved very closely with the CPI and on those grounds we use the CPI despite its theoretical shortcomings.

Center point, Central Business District (CBD) For each city we identified the center with the help of Google maps. All cities had a clear central area identifiable from the convergence of roads, the presence of a main railway station, clusters of hotels with the national chain name prefixed by "down town" and a concentration of signature institutions and monuments. We used the thus identified area to designate a city center, with one exception. For San Jose, we placed downtown in Silicon Valley.

The only city with more than one clear center was New York City, where midtown and downtown both can credibly claim that title. We picked the midtown center but locating the center downtown resulted in similar results. Because of this ambiguity, in a robustness test we exclude the New York metropolitan area and results are robust to this exclusion (Table 8 , column 3 ).

Within each center we picked a center point, a salient building or monument, and obtained its latitude and longitude from iTouchMap.com. For instance, for Washington DC, we picked the White House and for San Jose, Apple Inc. Headquarters. While there can be some discretion as to which coordinates represents the true center, most contenders would be within a mile or two of the points picked here. The list of center points are detailed in Table A2.

Distance to the CBD (dist) From tract shape files, we have generated latitude and longitude for the (population weighted) centroid of the tract, allowing us to calculate the distance between a tract and the CBD. We restrict our sample to tracts that are within 35 miles of the CBD.

In the preliminary analysis, we found our variables of interest to exhibit a pronounced $\mathrm{j}$-shape with respect to distance to the CBD, the minimum located somewhere in the 3-7 mile range. Therefore we chose a non-linear specification with distance indicator variables for the following intervals:

d1 $0-3$ miles

d2 3-10 miles

d3 10-20 miles

d4 20-35 miles, reference category.

FT Full Time We let $F T(h, e)$ denote the fraction of adults 25-55 who worked more that $h, h=40,50$ hours per week and had education $e, e=B A+, M A+$.

$Z$ Metropolitan Area Demand Shifter for Skilled Workers See description in Section 3.2

INCOME (Person) Total personal income (which can be negative). 


\section{V.2 Panel data set construction}

We use US2010 cross-walk files to create a tract-level panel data set, where for each tract in 2010 we construct its equivalent in previous years using cross-walk files from http://www.s4.brown.edu/us2010/Researcher/Bridging.htm. These files provide a mapping of tracts in a census year and 2010, as well as weights. For example, if there were a new tract $\mathrm{B}$ in 2010 that was the result of combining blocks from year 2000 tracts B1 and B2, then we would create a year 2000 tract B as a weighted average of B1 and B2. Thus, the ability to include tract fixed effects comes at the cost of data quality, and the problem worsens with the number of years to 2010 (more time allows for more changes to tracts). In order to explore the role of race, we are interested in parsing the sample by initial fraction blacks. Therefore, we restrict the sample to tracts for which we have an observation in 1980 and also remove tracts for which we only have one observation. We are left with a sample of about 48 thousand tracts (rounded to nearest '000 for disclosure reasons). 